\title{
Renal Association Clinical Practice Guidelines on Acute Kidney Injury
}

\author{
Dr Andrew Lewington ${ }^{a}$ and Dr Suren Kanagasundaram ${ }^{b}$ \\ ${ }^{a}$ Consultant Nephrologist, Leeds Teaching Hospitals, Leeds \\ ${ }^{\mathrm{b} C}$ Consultant Nephrologist, Freeman Hospital, Newcastle
}

\section{Key Words}

acute kidney injury - definition - epidemiology · prevention · treatment facilities - choice of renal replacement modality . vascular access - anticoagulation - therapy prescription . timing of initiation of therapy

\section{Introduction}

Acute kidney injury (AKI) has now replaced the term acute renal failure and an universal definition and staging system has been proposed to allow earlier detection and management of AKI. The new terminology enables healthcare professionals to consider the disease as a spectrum of injury. This spectrum extends from less severe forms of injury to more advanced injury when acute kidney failure may require renal replacement therapy (RRT). Clinically AKI is characterised by a rapid reduction in kidney function resulting in a failure to maintain fluid, electrolyte and acid-base homoeostasis. There have previously been many different definitions of AKI used in the literature which has made it difficult to determine the epidemiology and outcomes of AKI. Over recent years there has been increasing recognition that relatively small rises in serum creatinine in a variety of clinical settings are associated with worse outcomes [1].

To address the lack of an universal definition for AKI a collaborative network of international experts representing nephrology and intensive care societies established the Acute Dialysis Quality Initiative (ADQI) and devised the RIFLE definition and staging system for AKI [2]. Shortly after this many of the original members of the ADQI group collaborated to form the Acute Kidney Injury Network (AKIN) $[3,4]$. The AKIN group modified the RIFLE staging system to reflect the clinical significance of relatively small rises in serum creatinine.

Most recently the international guideline group, Kidney Disease: Improving Global Outcomes (KDIGO) has brought together international experts from many different specialties to produce a definition and staging system that harmonises the previous definitions and staging systems proposed by both ADQI and AKIN [5]. It is anticipated that this definition and staging system
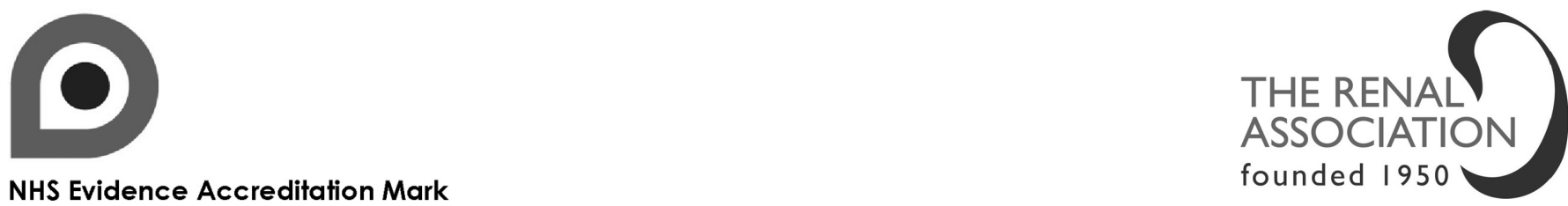

NHS Evidence Accreditation Mark

\section{KARGER}

Fax +4161306 1234 E-Mail karger@karger.ch www.karger.com
C 2011 S. Karger AG, Basel

$1018-8665 / 09 / 0000-0349 \$ 00.00 / 0$
Dr Andrew Lewington and Dr Suren Kanagasundaram

Email: Andrew.Lewington@leedsth.nhs.uk or Suren.Kanagasundaram@nuth.nhs.uk 
will be adopted globally. This will enable future comparisons of the incidence, outcomes and efficacy of therapeutic interventions for AKI.

To date there is a paucity of data on the incidence of AKI whether community or hospital-acquired. The reported prevalence of AKI from US data ranges from $1 \%$ (community-acquired) up to $7.1 \%$ (hospitalacquired) of all hospital admissions $[6,7]$. The population incidence of AKI from UK data ranges from 172 per million population ( $\mathrm{pmp}$ ) per year from early data [8] up to $486-630 \mathrm{pmp} / \mathrm{year}$ from more recent series [9-11], again depending on definition. The incidence of AKI requiring renal replacement therapy (RRT) ranges from $22 \mathrm{pmp} /$ year [7] to $203 \mathrm{pmp} /$ year [10]. An estimated $5-20 \%$ of critically ill patients experience an episode of AKI during the course of their illness and AKI receiving RRT has been reported in $49 \%$ of all admissions to intensive-care units (ICU) [12]. Data from the Intensive Care National Audit Research Centre (ICNARC) suggests that AKI accounts for nearly $10 \%$ of all ICU bed days [13].

Acute kidney injury is common in hospitalised patients and also has a poor prognosis with the mortality ranging from $10 \%-80 \%$ dependent upon the patient population studied. Patients who present with uncomplicated AKI, have a mortality rate of up to $10 \%$ [14, 15]. In contrast, patients presenting with AKI and multiorgan failure have been reported to have mortality rates of over $50 \%$. If renal replacement therapy is required the mortality rate rises further to as high as $80 \%[16,17]$.

Acute kidney injury is no longer considered to be an innocent bystander merely reflecting co-existent pathologies. It has been demonstrated to be an independent risk factor for mortality [18-20]. The cause of this is unclear but is possibly associated with an increased risk of 'non-renal' complications such as bleeding and sepsis [17]. An alternative explanation may lie in experimental work that has demonstrated the 'distant effects' of ischaemic AKI on the other organs. In these experimental models isolated ischaemic AKI upregulates inflammatory mediators in other organs including the brain, lungs and heart [21].

The UK National Confidential Enquiry into Patient Outcome and Death (NCEPOD) adding insult to injury acute kidney injury report was published last year [22]. This report examined the care of patients who died with a diagnosis of AKI. It identified many deficiencies in the care of patients who developed AKI and reported that only $50 \%$ of patients received good care. There was poor attention to detail, inadequate assessment of risk factors for AKI and an unacceptable delay in recognising post admission AKI. The report made a number of recommendations which included the following

- all emergency admissions should have a risk assessment for AKI

- all emergency admissions should have electrolytes checked on admission and appropriately thereafter

- predictable avoidable AKI should not occur

- all acute admission should receive adequate senior reviews (consultant review within 12 hours)

- there should be sufficient critical care and renal beds to allow rapid step up care

- undergraduate medical training should include the recognition of the acutely ill patient and the prevention, diagnosis and management of AKI

- postgraduate training in all specialties should include training in the detection, prevention and management of AKI.

The NCEPOD report was used to support a successful proposal made to the National Institute for Health and Clinical Excellence (NICE) for an AKI guideline. It is hoped that the guideline will be available in the near future.

Once a patient has developed AKI the therapeutic options are limited with the mainstay of treatment being renal replacement therapy (RRT). However there are many important aspects surrounding the care of a patient with AKI that must be considered which include timely referral and transfer to renal services if appropriate. There is a paucity of evidence to guide the optimal time to initiate RRT and the decision remains the choice of the individual physician. If a patient commences RRT then there are number of practical issues to be considered including the modality, the choice of filter membrane, the optimal site of vascular access, anticoagulation and the intensity of the treatment. The purpose of these clinical practice guidelines is to review the available evidence and provide a pragmatic approach to the patient with AKI. There is a pressing need for renal physicians to engage in undergraduate and postgraduate educational programmes to improve the current management of AKI. 


\section{References}

$>1$ Praught ML, Shlipak MG. Are small changes in serum creatinine an important risk factor? Curr Opin Nephrol Hypertens 2005;14:265-270

$\checkmark 2$ Bellomo R, Ronco C, Kellum JA, Mehta RL, Palevsky P, and the ADQI workgroup. Acute renal failure - definition, outcome measures, animal models, fluid therapy and information technology needs. The second international consensus conference of Acute Dialysis Quality Initiative (ADQI) Group. Crit Care 2004;8:R204-R212

$\checkmark 3$ Mehta RL, Kellum JA, Shah SV, et al. Acute Kidney Injury Network (AKIN): report of an initiative to improve outcomes in acute kidney injury. Crit. Care 2007;11:R31

$\checkmark 4$ Molitoris BA, Levin A, Warnock D, et al. Improving outcomes of acute kidney injury: report of an initiative. Nat Clin Pract Nephrol 2007;3 [8]: 439-442

5 Kidney Disease: Improving Global Outcomes. Clinical practice guideline on acute kidney injury. 2011. www.kdigo.org

6 Nash K, Hafeez A, Hou S. Hospital-acquired renal insufficiency. Am J Kidney Dis 2002;39:930-936

7 Kaufman J, Dhakal M, Patel B, et al. Community-acquired acute renal failure. Am J Kidney Dis 1991;17:191-198

$>8$ Feest TG, Round A, Hamad S. Incidence of severe acute renal failure in adults: results of a living community based study. BMJ 1993;306:481483

$\checkmark 9$ Stevens PE, Tamimi NA, Al Hasani MK, et al. Non-specialist management of acute renal failure. QJM 2001;94:533-540

10 Metcalfe W, Simpson KM, Khan IH, et al. Acute renal failure requiring renal replacement therapy: incidence and outcome. QJM 2002;95:579_ 583

11 Hegarty J, Middleton R, Krebs M et al. Severe acute renal failure. Place of care, incidence and outcomes. QJM 2005;98:661-666
12 Metnitz PGH, Krenn CG, Steltzer H, et al. Effect of acute renal failure requiring renal replacement therapy on outcome in critically ill patients. Crit Care Med 2002;30:2051-2058

13 Intensive-Care National Audit Research Centre 2005 www.icnarc.org

14 Hou SH, Bushinsky DA, Wish JB, Cohen JJ, Harrington JT. Hospitalacquired renal insufficiency: a prospective study. Am J Med 1983;74: 243-248

15 Shusterman N, Strom BL, Murray TG, Morrison G, West SL, Maislin G. Risk factors and outcome of hospital-acquired acute renal failure. Clinical epidemiologic study. Am J Med 1987;83:65-71

16 Liaño F, Junco E, Pascual J, Madero R, Verde E. The spectrum of acute renal failure in the intensive care unit compared with that seen in other settings. The Madrid Acute Renal Failure Study Group. Kidney Int 1998;53:S16-S24

17 Cosentino F, Chaff C, Piedmonte M. Risk factors influencing survival in ICU acute renal failure. Nephrol Dial Transplant 1994;9:179-182

18 Chertow GM, Levy EM, Hammermeister KE et al. Independent association between acute renal failure and mortality following cardiac surgery. Am J Med 1998;104:343-348

19 Levy EM, Viscoli CM, Horwitz RI. The effect of acute renal failure on mortality: a cohort analysis. JAMA 1996;275:1489-1494

20 Uchino S, Bellomo R, Goldsmith D et al. An assessment of the RIFLE criteria for acute renal failure in hospitalized patients. Crit Care Med 2006;34:1913-1917

21 Li X, Hassoun HT, Santora R, Rabb H. Organ crosstalk: the role of the kidney. Curr Opin Crit Care. 2009 Dec;15[6]:481-487

22 National Confidential Enquiry into Patient Outcome and Death, Adding Insult to Injury 2009. www.ncepod.org 


\section{Summary of Clinical Practice Guideline on Acute Kidney Injury}

\section{Acute Kidney Injury (AKI) (Guidelines AKI} 1.1-1.3)

\section{Guideline 1.1 - AKI: Definition, Epidemiology and} Outcomes

We recommend that the international Kidney Disease: Improving Global Outcomes (KDIGO) definition of acute kidney injury (AKI) should be adopted. (Not Graded)

Acute kidney injury is defined when one of the following criteria is met

- Serum creatinine rises by $\geqslant 26 \mu \mathrm{mol} / \mathrm{L}$ within 48 hours or

- Serum creatinine rises $\geqslant 1.5$ fold from the reference value, which is known or presumed to have occurred within one week or

- urine output is $<0.5 \mathrm{ml} / \mathrm{kg} / \mathrm{hr}$ for $>6$ consecutive hours

The reference serum creatinine should be the lowest creatinine value recorded within 3 months of the event.

If a reference serum creatinine value is not available within 3 months and AKI is suspected

- repeat serum creatinine within 24 hours

- a reference serum creatinine value can be estimated from the nadir serum creatinine value if patient recovers from AKI

\section{Guideline 1.2 - AKI: Definition, Epidemiology and Outcomes}

We recommend that the international Kidney Disease: Improving Global Outcomes (KDIGO) staging classification $^{*}$ of acute kidney injury (AKI) should be adopted. (Not Graded)
Guideline 1.3 - AKI: Definition, Epidemiology and Outcomes

We recommend that serum creatinine and urine output remain the best biomarkers for AKI. Serum creatinine should be measured using the enzymatic technique. (1B)

\section{Acute Kidney Injury (AKI) (Guidelines AKI}

2.1-2.2)

Guideline 2.1 - AKI: Clinical Assessment; History, Examination

We recommend that all patients presenting with AKI should have a comprehensive history and examination performed to help determine the aetiology of the AKI. (1A)

\section{Guideline 2.2 - AKI: Clinical Assessment; Investigations}

We recommend that all patients presenting with AKI should have appropriate baseline investigations performed which should include a urinalysis and a renal tract ultrasound within 24 hours (if renal tract obstruction is suspected). (1A)

\section{Acute Kidney Injury (AKI) (Guidelines AKI 3.1-3.4)}

\section{Guideline 3.1 - AKI: Prevention; Risk Assessment}

We recommend that patients at risk of AKI should be identified and appropriate preventative measures should be instituted as early as possible. (1B)

\section{Guideline 3.2 - AKI: Prevention; Fluid Therapy}

We recommend that prescription of appropriate intravenous fluid should be carefully considered following assessment of the patient's volume status. Thereafter the patient's clinical response should be monitored closely. (1B)

\begin{tabular}{|c|c|c|}
\hline Stage & Serum creatinine (SCr) criteria & Urine output criteria \\
\hline 1 & $\begin{array}{l}\text { increase } \geqslant 26 \mu \mathrm{mol} / \mathrm{L} \text { within } 48 \mathrm{hrs} \text { or } \\
\text { increase } \geqslant 1.5 \text { to } 1.9 \mathrm{X} \text { reference } \mathrm{SCr}\end{array}$ & $<0.5 \mathrm{~mL} / \mathrm{kg} / \mathrm{hr}$ for $>6$ consecutive hrs \\
\hline 2 & increase $\geqslant 2$ to $2.9 \mathrm{X}$ reference $\mathrm{SCr}$ & $<0.5 \mathrm{~mL} / \mathrm{kg} / \mathrm{hr}$ for $>12 \mathrm{hrs}$ \\
\hline 3 & $\begin{array}{l}\text { increase } \geqslant 3 X \text { reference } S C r \text { or } \\
\text { increase } \geqslant 354 \mu \mathrm{mol} / \mathrm{L} \text { or } \\
\text { commenced on renal replacement therapy (RRT) irrespective of stage }\end{array}$ & $<0.3 \mathrm{~mL} / \mathrm{kg} / \mathrm{hr}$ for $>24 \mathrm{hrs}$ or anuria for $12 \mathrm{hrs}$ \\
\hline
\end{tabular}

* must have met initial criteria for definition of AKI 
Guideline 3.3 - AKI: Prevention; Contrast-Induced AKI (CI-AKI)

We recommend that patients identified as being at risk of contrast induced-AKI (CI-AKI) should have a careful assessment of volume status and receive pre-procedure volume expansion with $0.9 \%$ sodium chloride or isotonic sodium bicarbonate if clinically indicated. (1A)

\section{Guideline 3.4 - AKI: Prevention; AKI secondary to} Rhabdomyolysis

We recommend that patients identified as being at risk of developing AKI secondary to rhabdomyolysis should receive intravenous volume expansion with $0.9 \%$ sodium chloride and sodium bicarbonate. (1B)

\section{Acute Kidney Injury (AKI) (Guidelines AKI} 4.1-4.5)

\section{Guideline 4.1 - AKI: Management; General Management}

We recommend that general supportive measures include optimisation of haemodynamic status by appropriate fluid therapy, administration of vasopressors and/or inotropes and treatment of any underlying sepsis. Nephrotoxic medications should be stopped. (1A)

Guideline 4.2 - AKI: Management; Pharmacological Therapy

We recommend that therapeutic drug dosing must be adapted to altered kinetics in AKI. (1B)

Guideline 4.3 - AKI: Management; Pharmacological Therapy

We recommend that there is no specific pharmacological therapy proven to effectively treat AKI secondary to hypoperfusion injury and/or sepsis. (1B)

\section{Guideline 4.4 - AKI: Management; Nutritional Support}

We recommend that patients with AKI receiving renal replacement therapy (RRT) should be referred to a dietician for individual assessment. (1D)

\section{Guideline 4.5 - AKI: Management; Nutritional Support}

We recommend that patients with AKI should receive $25-35 \mathrm{kcal} / \mathrm{kg} /$ day and up to a maximum of $1.7 \mathrm{~g}$ amino acids $/ \mathrm{kg} /$ day if hypercatabolic and receiving continuous renal replacement therapy. Trace elements and water soluble vitamins should be supplemented as required. (1C)

\section{Acute Kidney Injury (AKI) (Guidelines AKI 5.1-5.7)}

Guideline 5.1 - AKI: Treatment facilities and referral to renal services

We recommend that renal services should work together with other specialties to develop guidelines for the management of AKI. These should include clear guidelines with respect to when to request a renal referral. (1A)

Guideline 5.2 - AKI: Treatment facilities and referral to renal services

We recommend that specialist renal advice should be given with consultant renal physician input. (1B)

\section{Guideline 5.3 - AKI: Treatment facilities and referral} to renal services

We recommend that transfer protocols should be developed based on local physiological early warning scores to ensure appropriate triage of in-patients with AKI arriving from other hospitals. (1C)

\section{Guideline 5.4-AKI: Treatment facilities and referral} to renal services

We recommend that physiological surveillance should be performed for all patients with AKI to identify early signs of physiological deterioration which may require escalation in the level of care. $(1 \mathrm{~A})$

\section{Guideline 5.5 - AKI: Treatment facilities and referral to renal services}

We suggest that renal physicians and intensivists should work together to provide care for patients with AKI on the intensive care unit (ICU). Nephrology trainees should be trained to care for acutely ill patients with AKI. (2C)

\section{Guideline 5.6 - AKI: Treatment facilities and referral} to renal services

We suggest that intensive care units should contact renal services to discuss patients likely to require ongoing single organ renal support prior to step-down. Advance warning of such patients will facilitate forward planning and continued follow-up. (2C)

\section{Guideline 5.7-AKI: Treatment facilities and referral} to renal services

We recommend that AKI survivors with residual renal impairment should be managed according to local chronic kidney disease (CKD) guidelines. Discharge 
planning should include plans for CKD management, where relevant. (1A)

\section{Acute Kidney Injury (AKI) (Guideline AKI 6.1)}

\section{Guideline 6.1 - AKI: Choice of renal replacement} therapy modality

We recommend that the choice of renal replacement therapy modality should be guided by the individual patient's clinical status, medical and nursing expertise, and availability of modality. (1B)

\section{Acute Kidney Injury (AKI) (Guidelines AKI} 7.1-7.3)

\section{Guideline 7.1 - AKI: Choice of dialyser/haemofilter membrane}

We recommend that synthetic or modified cellulosic membranes should be used in preference to unmodified cellulose membranes. (1B)

\section{Guideline 7.2 - AKI: Choice of dialysate/replacement fluid}

We recommend that bicarbonate should be the preferred buffer for dialysate and replacement fluid in continuous renal replacement therapy (CRRT) techniques unless regional citrate anticoagulation is employed. (1C)

Guideline 7.3 - AKI: Microbial standards for fluids

We recommend that microbial standards for fluids used for chronic haemodialysis (HD)/haemodiafiltration (HDF) should be also applied to extracorporeal therapy for AKI. (1A)

\section{Acute Kidney Injury (AKI) (Guidelines AKI 8.1-8.9)}

\section{Guideline 8.1 - AKI: Vascular access for RRT}

We recommend that acute access for renal replacement therapy should be veno-venous rather than arterio-venous. (1A)

\section{Guideline 8.2 - AKI: Vascular access for RRT}

We recommend that dialysis catheters should be of an adequate length to minimise the risks of access recirculation. (1C)

\section{Guideline 8.3 - AKI: Vascular access for RRT}

We suggest that the access site and catheter type should be chosen with regard to the phase of the patient's illness. (2C)
Guideline 8.4 - AKI: Vascular access for RRT

We recommend that access should be placed by experienced or appropriately supervised staff. Real-time ultrasound guidance should be used to aid placement of upper body access. (1A)

\section{Guideline 8.5 - AKI: Vascular access for RRT}

We recommend that it is advisable that real-time ultrasound guidance be used for the insertion of femoral access. (1D)

\section{Guideline 8.6 - AKI: Vascular access for RRT}

We recommend that subclavian access should be avoided in patients at risk of progressing to CKD stage 4 or 5 due to the risks of compromising future, permanent vascular access. (1D)

\section{Guideline 8.7 - AKI: Vascular access for RRT}

We suggest that non-dominant arm upper limb vasculature should be preserved as a contingency for future permanent access. (2C)

\section{Guideline 8.8 - AKI: Vascular access for RRT}

We recommend that temporary access should be changed at appropriate intervals (as per local protocol) to minimise the risk of infection. (1C)

\section{Guideline 8.9 - AKI: Vascular access for RRT}

We suggest that local policies on prevention of catheter-related infection should be optimised by reserving the catheter for extracorporeal treatment only. (2D)

\section{Acute Kidney Injury (AKI) (Guidelines AKI 9.1-9.4)}

\section{Guideline 9.1 - AKI: Anticoagulation for extracorporeal therapies}

We recommend that anticoagulation for RRT should be tailored according to patient characteristics and the modality of RRT chosen. (1C)

\section{Guideline 9.2 - AKI: Anticoagulation for extracorporeal therapies}

We recommend that regional anticoagulation with citrate reduces risk of haemorrhage compared to systemic heparinisation. The complexity of the technique means that this should be in routine use on any unit on which it is employed in order to allow sufficient levels of expertise to be maintained. (1C) 
Guideline 9.3 - AKI: Anticoagulation for

extracorporeal therapies

We suggest that prostacyclin is a suitable alternative to unfractionated heparin in those at increased risk of bleeding but may cause haemodynamic instability. (2C)

\section{Guideline 9.4 - AKI: Anticoagulation for} extracorporeal therapies

We suggest that a no-anticoagulation, saline flush strategy can be used in patients receiving continuous and intermittent RRT who are at high risk of bleeding. However, ultrafiltration requirements are increased, effective intermittent HD time is reduced and the technique runs the risk of membrane fibre rupture. $(2 \mathrm{C})$

\section{Acute Kidney Injury (AKI) (Guidelines AKI 10.1-10.5)}

\section{Guideline 10.1 - AKI: Renal Replacement Therapy prescription}

We recommend that the delivered dose of RRT should be assessed to ensure the adequacy of the prescription. (1A)

\section{Guideline 10.2 - AKI: Renal Replacement Therapy prescription}

We recommend that the prescribed dose should be assessed at each session (for intermittent haemodialysis) and daily (for continuous RRT) to account for any measured shortfalls in delivered dose. (1A)

\section{Guideline 10.3 - AKI: Renal Replacement Therapy prescription}

We recommend that patients with AKI and multiorgan failure treated by continuous renal replacement therapy (CRRT) should receive treatment doses equivalent to post dilution ultrafiltration rates $\geqslant 25 \mathrm{ml} / \mathrm{kg} / \mathrm{hr}$. A proportionate upward adjustment to the prescribed ultrafiltration rate should be made in pre-dilutional continuous haemofiltration. (1A)

\section{Guideline 10.4 - AKI: Renal Replacement Therapy prescription}

We recommend that patients with AKI and multiorgan failure treated by intermittent haemodialysis should receive either alternate day haemodialysis with at least the minimum dose considered appropriate for end-stage renal disease (ESRD), urea reduction ratio (URR) $>65 \%$ or $\mathrm{eKt} / \mathrm{V}>1.2$ or daily haemodialysis. (1B)
Guideline 10.5 - AKI: Renal Replacement Therapy prescription

We suggest that renal replacement therapy dosing methods that require an assessment of patient weight should use a measured weight rather than an extrapolated weight from pre-morbid readings. (2B)

\section{Acute Kidney Injury (AKI) (Guidelines AKI 11.1-11.5)}

\section{Guideline 11.1 - AKI: Timing of initiation of renal} replacement treatment

We recommend that the decision to start RRT in patients with AKI should remain a clinical decision based on fluid, electrolyte and metabolic status of each individual patient. (1C)

\section{Guideline 11.2 - AKI: Timing of initiation of renal replacement treatment}

We recommend that RRT should be initiated once AKI is established and unavoidable but before overt complications have developed. (1B)

\section{Guideline 11.3 - AKI: Timing of initiation of renal replacement treatment}

We recommend that the threshold for initiating RRT should be lowered when AKI occurs as part of multiorgan failure. (1C)

\section{Guideline 11.4 - AKI: Timing of initiation of renal replacement treatment}

We recommend that the initiation of RRT may be deferred if the underlying clinical condition is improving and there are early signs of renal recovery. (1D)

\section{Guideline 11.5 - AKI: Timing of discontinuation of renal replacement treatment}

We recommend that an improvement in the patient's clinical condition and urine output would justify temporary discontinuation of ongoing renal support to see if AKI is recovering. (1D)

\section{Acute Kidney Injury (AKI) (Guideline AKI 12.1)}

\section{Guideline 12.1 - AKI: Education}

We recommend that undergraduate and postgraduate medical trainees should be taught the principles of prevention, recognition and management of AKI. (1C) 


\section{Summary of Audit Measures}

It is recommended that the following audit measures are recorded for all patients diagnosed with acute kidney injury. However it is recognised that it may only be possible for renal units to record these audit measures for patients that have been referred for a renal specialist opinion.

The Renal Association encourages other specialties to record these audit measures for all patients diagnosed with AKI irrespective of whether or not they are referred to renal services. From a pragmatic point of view in terms of available resources it is proposed that other specialties initially collect data on patients with AKI stage 3 . Once a robust data collection system has been established an incremental collection of data extending to AKI stage 2 and then AKI stage 1 could follow.

1. Incidence and outcomes of patients diagnosed with

- community-acquired AKI

- hospital acquired AKI

2. Incidence and outcomes of patients with different causes of AKI

3. Incidence of acute admissions/patients undergoing major surgery who had

- the risk of AKI assessed on admission/presurgery

- electrolytes checked on admission/pre-surgery and rechecked within 24 hours

4. Proportion of patients who had a urinalysis performed within 24 hours of the diagnosis of AKI unless anuric

5. Proportion of patients where there has been a delay of $>48$ hours in recognising the diagnosis of AKI

6. Proportion of patients developing AKI secondary to obstruction who had a renal ultrasound examination $<24 \mathrm{hrs}$ after a diagnosis of AKI established

7. Proportion of patients with or at risk of AKI who are prescribed intravenous fluids without an assessment of volume status

8. Proportion of patients with AKI who did not have the appropriate adjustment of medication doses

9. Proportion of patients with or at risk of AKI who receive nephrotoxic medications

10. Proportion of patients at high risk of contrast induced AKI (CI-AKI) who developed AKI and did not
- receive pre-procedure volume assessment

- receive appropriate volume expansion

- have appropriate adjustments to medications

11. Proportion of patients with severe AKI where there is documented evidence of patient involvement in decision making with respect to commencing renal replacement therapy (RRT)

12. Incidence of delays of transfer of patients with AKI $>24$ hours following referral to renal services due to a lack of resources on renal unit

13. Incidence of patients with single organ AKI admitted to ICU for RRT due to a lack of resources on the renal unit

14. Number of AKI inpatient transfers requiring escalation of care within 24 hours of arrival on renal unit

15. Incidence of dialysis catheter-related bacteraemia and sepsis in patients with AKI

16. Incidence of heparin induced thrombocytopenia

17. Proportion of critically ill patients with AKI treated with alternate day haemodialysis who receive $\mathrm{eKt} / \mathrm{V} \geqslant 1.2$ per session

18. Proportion of critically ill patients with AKI treated with continuous renal replacement therapy who receive $>25 \mathrm{mls} / \mathrm{kg} / \mathrm{hr}$ post dilution ultrafiltration

19. Proportion of patients with AKI receiving renal replacement therapy reviewed by dietician within 24 hours

20. Proportion of patients with AKI receiving renal replacement therapy prescribed the recommended nutritional support

21. Proportion of patients with AKI who recover kidney function within 90 days of episode as defined by

- return of serum creatinine to within $20 \%$ of baseline value (most recent value within 3 months but accepting value up to one year)

- dialysis independence (if previously requiring dialysis)

22. Proportion of AKI survivors with residual chronic kidney disease with post-discharge CKD planning

23. Proportion of AKI survivors who are given information on the cause of AKI and how this might be avoided in the future

24. Outcome measures for patients developing AKI should include

- length of hospital stay

- hospital mortality

- 90 day mortality

- one year mortality 


\section{Rationale for Clinical Practice Guideline on Acute Kidney Injury}

\section{Acute Kidney Injury (AKI) (Guidelines AKI 1.1-1.3)}

\section{Guideline 1.1 - AKI: Definition, Epidemiology and Outcomes}

We recommend that the international Kidney Disease: Improving Global Outcomes (KDIGO) definition of acute kidney injury (AKI) should be adopted. (Not Graded)

\section{Audit measures}

1. Incidence and outcomes of patients diagnosed with

- community-acquired AKI

- hospital acquired AKI

2. Proportion of patients where there has been a delay of $>48$ hours in recognising the diagnosis of AKI

3. Proportion of patients with AKI who recover kidney function within 90 days of episode as defined by

- return of serum creatinine to within $20 \%$ of baseline value (most recent value within 3 months but accepting up to one year)

- dialysis independence (if previously requiring dialysis)

4. Outcome measures for patients developing AKI should include

- length of hospital stay

- hospital mortality

- 90 day mortality

- one year mortality

\section{Rationale}

Over recent years it has been recognised that even small increases in serum creatinine ( $\mathrm{SCr}$ ) are associated with worse patient outcomes [1]. To reflect the importance of these changes in SCr the term acute kidney injury (AKI) has now replaced acute renal failure (ARF). This allows AKI to be considered as a spectrum of severity that if not detected or recognised in its early stages may ultimately result in acute kidney failure and the need for renal replacement therapy (RRT).

The most recent definitions proposed by the Acute Dialysis Quality Initiative (ADQI), RIFLE, and the Acute Kidney Injury Network (AKIN) have been based on rises in serum creatinine or reductions in urine output. These definitions aimed to promote the earlier detection and recognition of AKI triggering appropriate treatment prior to progressive injury and kidney failure.
The application of these definitions in more than 500,000 patients has validated the increased risk of mortality associated with developing AKI [2-4]. These studies have also indicated that the incidence of AKI in hospitalised patients may be as high as $18 \%$. These definitions have recently been harmonised by the Kidney Diseases: Improving Global Outcomes International (KDIGO) guideline group [5].

It is important to note that the diagnosis of AKI should be made initially based on the definition below. Once the diagnosis of AKI has been established its severity can be determined using the staging system (shown in Table 1 in the rationale for guideline recommendation $1.2)$.

Acute kidney injury is defined when one of the following criteria is met

- Serum creatinine rises by $\geqslant 26 \mu \mathrm{mol} / \mathrm{L}$ within 48 hours or

- Serum creatinine rises $\geqslant 1.5$ fold from the reference value, which is known or presumed to have occurred within one week or

- urine output is $<0.5 \mathrm{ml} / \mathrm{kg} / \mathrm{hr}$ for $>6$ consecutive hours

The reference serum creatinine should be the lowest creatinine value recorded within 3 months of the event.

If a reference serum creatinine value is not available within 3 months and AKI is suspected

- repeat serum creatinine within 24 hours

- a reference serum creatinine value can be estimated from the nadir serum creatinine value if patient recovers from AKI

It is recognised that outside of ICU the accuracy of urine output measurements will be less reliable. The use of urine output criteria for both the diagnosis and staging of AKI has been less well studied. Clinical judgement is necessary in patient assessment and the recognition that patients may develop oliguric as well as nonoliguric AKI.

\section{Guideline 1.2 - AKI: Definition, Epidemiology and Outcomes}

We recommend that the international Kidney Disease: Improving Global Outcomes (KDIGO) staging classification of acute kidney injury (AKI) should be adopted. (Not Graded) 
Table 1. KDIGO staging system for acute kidney injury

\begin{tabular}{|c|c|c|}
\hline Stage & Serum creatinine (SCr) criteria & Urine output criteria \\
\hline 1 & $\begin{array}{l}\text { increase } \geqslant 26 \mu \mathrm{mol} / \mathrm{L} \text { within } 48 \mathrm{hrs} \text { or } \\
\text { increase } \geqslant 1.5 \text { to } 1.9 \mathrm{X} \text { reference } \mathrm{SCr}\end{array}$ & $<0.5 \mathrm{~mL} / \mathrm{kg} / \mathrm{hr}$ for $>6$ consecutive hrs \\
\hline 2 & increase $\geqslant 2$ to $2.9 \mathrm{X}$ reference $\mathrm{SCr}$ & $<0.5 \mathrm{~mL} / \mathrm{kg} / \mathrm{hr}$ for $>12 \mathrm{hrs}$ \\
\hline 3 & $\begin{array}{l}\text { increase } \geqslant 3 \mathrm{X} \text { reference } \mathrm{SCr} \text { or } \\
\text { increase } \geqslant 354 \mu \mathrm{mol} / \mathrm{L} \text { or } \\
\text { commenced on renal replacement therapy (RRT) irrespective of stage }\end{array}$ & $<0.3 \mathrm{~mL} / \mathrm{kg} / \mathrm{hr}$ for $>24 \mathrm{hrs}$ or anuria for $12 \mathrm{hrs}$ \\
\hline
\end{tabular}

\section{Rationale}

The application of both the RIFLE and AKIN staging systems to patient populations have demonstrated that as the stage of AKI increases so does the risk of mortality [2-4]. Acute kidney injury staging can be performed using serum creatinine or urine output criteria (Table 1). Patients should be staged according to whichever criteria (serum creatinine or urine output) gives them the highest stage and only after they have been identified as meeting the criteria for the definition of AKI.

\section{Guideline 1.3 - AKI: Definition, Epidemiology and Outcomes}

We recommend that serum creatinine and urine output remain the best biomarkers for AKI. Serum creatinine should be measured using the enzymatic technique. (1B)

\section{Rationale}

It is recognised that serum creatinine represents a poor biomarker. An acute decline in kidney function may not be reflected by a rise in serum creatinine for several hours. Routine methods for the measurement of serum creatinine are based on the Jaffe reaction, first described in 1886 [6]. Since then the method has been refined many times to try and overcome inherent problems of analytical interference. In addition, to problems of analytical interference, there is large variation in reported creatinine concentrations using differing methods [7] that reflect calibration differences. The recent introduction of estimated GFR (eGFR) has emphasised the requirement for inter-laboratory agreement of serum creatinine results. In Vitro Diagnostics (IVDs) have largely adopted calibration of their methods to be traceable to Isotope Dilution Mass Spectrometry (IDMS) as recommended by expert professional groups such as the laboratory working group of the National Kidney Disease Education Program (NKDEP) [8]. Whilst this will reduce inter-laboratory bias, it will not resolve problems of analytical interference and imprecision.

Numerous endogenous substances are known to interfere with different Jaffe reaction based assays. These include positive interferents such as protein, ascorbate, pyuvate, glucose and cephalosporins [9] and negative interferents such as bilirubin [9]. Enzymatic assays, utilising the enzymes, creatininase, creatinase and sarcosine oxidase are much less prone to such interference [9]. Replacement of Jaffe reaction based serum creatinine assays with the enzymatic assay and calibration using IDMS calibrators should significantly improve interlaboratory agreement of serum creatinine assays.

There is clearly a need to find better, alternative bio-markers to serum creatinine. Serum and/or urinary biomarkers currently being researched include neutrophil gelatinase-associated lipocalin (NGAL), Kidney Injury Molecule-1 (KIM-1), interleukin-18 (IL-18), and cystatin C [10-14]. There have been a variety of publications demonstrating their utility in detecting AKI in different patient cohorts. However further work is still required to understand their application before they can be recommended as superior to serum creatinine. 


\section{References}

1 Praught ML, Shlipak MG. Are small changes in serum creatinine and important risk factor? Current Opinions in Nephrology and Hypertension 2005;14:265-270

-2 Hoste EA, Clermont G, Kersten A, Venkataraman R, Angus DC, De Bacquer D, Kellum JA. RIFLE criteria for acute kidney injury are associated with hospital mortality in critically ill patients: a cohort analysis. Crit Care. 2006;10[3]:R73. Epub 2006 May 12.

-3 Uchino S, Bellomo R, Goldsmith D, Bates S, Ronco C. An assessment of the RIFLE criteria for acute renal failure in hospitalized patients. Crit Care Med. 2006 Jul;34[7]:1913-1917.

4 Thakar CV, Christianson A, Freyberg R, Almenoff P, Render ML. Incidence and outcomes of acute kidney injury in intensive care units: a Veterans Administration study. Crit Care Med. 2009 Sep;37[9]: 2552-2558.

5 Kidney Disease: Improving Global Outcomes. Clinical practice guideline on acute kidney injury. 2011. www.kdigo.org

6 Jaffe M. Uber den niederschlag, welchen pikrinsaure in normalen hrn erzgeugt und uber eine neue reaction des kreatinins. Z Physiol Chem 1886;10:391-400

7 Lawson N, Lang T, Broughton A, Prinsloo P, Turner C, Marenah C. Creatinine assays: time for action? Ann Clin Biochem 2002;39:599602
$>8$ Recommendations for improving serum creatinine measurement: A report from the laboratory working group of the National Kidney Disease Education Preogram. Clin Chem 2006;52:5-18

9 Peake M, Whiting M. Measurement of serum creatinine-current status and future goals. Clin Biochem Rev 2006;27:173-184

10 Hewitt SM, Dear J, Star RA. Discovery of protein biomarkers for renal diseases. J Am Soc Nephrol. 2004;15[7]:1677-1689

11 Vaidya VS, Ramirez V, Ichimura T, Bobadilla NA, Bonventre JV. Urinary kidney injury molecule-1: a sensitive quantitative biomarker for early detection of kidney tubular injury. Am J Physiol Renal Physiol 2006; 290[2]:F517-F529

12 Parikh CR, Mishra J, Thiessen-Philbrook H, Dursun B, Ma Q, Kelly C, Dent C, Devarajan P, Edelstein CL. Urinary IL-18 is an early predictive biomarker of acute kidney injury after cardiac surgery. Kidney Int 2006;70:199-203

13 Mishra J, Ma Q, Prada A, Mitsnefes M, Zahedi K, Yang J, Barasch J, Devarajan P. Identification of Neutrophil Gelatinase-Associated Lipocalin as a Novel Early Urinary Biomarker for Ischemic Renal Injury. J Am Soc Nephrol 2003;14:2534-2543

14 Herget-Rosenthal S, Marggraf G, Husing J, Goring F, Pietruck F, Janssen O, Philipp T, Kribben A. Early detection of acute renal failure by serum cystatin C. Kidney Int 2004;66:1115-1122 


\section{Acute Kidney Injury (AKI) (Guidelines AKI}

2.1-2.2)

Guideline 2.1 - AKI: Clinical Assessment; History,

\section{Examination}

We recommend that all patients presenting with AKI should have a comprehensive history and examination performed to help determine the cause of the AKI. (1A)

\section{Audit measure}

1. Incidence and outcomes of patients with different causes of AKI

\section{Rationale}

Acute kidney injury is most frequently caused by ischaemia, sepsis or nephrotoxic insults to the kidney. In patients with hospital-acquired AKI the cause is frequently multi-factorial in patients with multiple risk factors. However it is essential to consider the underlying cause of AKI as a smaller percentage of cases may be caused by acute interstitial nephritis or acute glomerulonephritis which will require specific therapy [1]. It is hoped that earlier detection and recognition of AKI may provide an earlier opportunity to provide specific therapy to these forms of esoteric AKI [2].

Clinical assessment of the patient with AKI starts with a comprehensive history including a review of:

- patient notes

- AKI risk factors

$\circ$ age $>75$ yrs

- chronic kidney disease (CKD, eGFR $<60 \mathrm{mls} /$ $\mathrm{min} / 1.73 \mathrm{~m}^{2}$ )

- Cardiac failure

- Atherosclerotic peripheral vascular disease

- Liver disease

- Diabetes mellitus

- Nephrotoxic medications

- potential causes for AKI including

- reduced fluid intake

- increased fluid losses

$\circ$ urinary tract symptoms

$\circ$ recent drug ingestion

o sepsis

- systemic clinical features

$\circ$ fever

$\circ$ rash

$\circ$ joint pains

Clinical examination must include
- general

$\circ$ rash

$\circ$ uveitis

$\circ$ joint swelling

- assessment of volume status

- core temperature

$\circ$ peripheral perfusion

$\circ$ heart rate

- blood pressure

- jugular venous pressure

- signs of renovascular disease

$\circ$ audible bruits

- impalpable peripheral pulses

- abdominal examination

- palpable bladder

\section{Guideline 2.2 - AKI: Clinical Assessment; Investigations}

We recommend that all patients presenting with AKI should have appropriate baseline investigations performed which should include a urinalysis and a renal tract ultrasound within 24 hours (if renal tract obstruction is suspected). (1A)

\section{Audit measures}

1. Proportion of patients who had a urinalysis performed within 24 hours of the diagnosis of AKI unless anuric

2. Proportion of patients developing AKI secondary to obstruction who had a renal ultrasound examination $<24 \mathrm{hrs}$ after a diagnosis of AKI established

\section{Rationale}

Clinical assessment to establish a working diagnosis requires a number of investigations to be performed.

A baseline set of laboratory investigations should be sent including:

- biochemistry

$$
\text { - Urea and electrolytes }
$$

- haematology

- FBC

- urinalysis ( \pm microscopy)

- microbiology

$\circ$ urine culture (if infection is suspected)

$\circ$ blood culture (if infection is suspected)

More specific renal investigations are dependent upon the clinical presentation and may include:

- renal immunology 
- urinary biochemistry

○ electrolytes

$\circ$ osmolality

- ECG

- chest X-ray

- abdominal X-ray

- renal tract ultrasound (within $24 \mathrm{hrs}$ if obstruction suspected or esoteric cause suspected requiring a kidney biopsy)

- kidney biopsy

Urinalysis can provide important clinical information to patients with AKI. Positive protein values of $3+$ and $4+$ on reagent strip testing of the urine suggest intrinsic glomerular disease. A reagent strip positive for blood suggests the presence of red blood cells ( $>5 /$ high power field). Although red cell morphology may not be particularly useful [3] the observation of large numbers of red cells in the presence of proteinuria suggests a glomerular aetiology for AKI. The suspicion is strengthened by the finding of red cell casts on a freshly collected sample of urine (this is rarely performed in the UK).

Haematuria may also be found in cases of lower urinary tract obstruction often in association with tumours and less commonly associated with calculi, infection or severe renal ischaemia due to arterial or venous thrombosis. Characteristically myoglobinuria will cause a positive reagent strip reaction for haematuria without evidence of red cells on urine microscopy.

Increased numbers of white cells $(>5$ per high power field) are non-specific but are found more commonly with acute interstitial nephritis, infection and glomerulonephritis. Eosinophiluria is not a very specific test for interstitial nephritis and has a very poor positive predictive value. However, the value of eosinophiluria in interstitial nephritis is in ruling out the disease, the negative predictive value for patients with AKI is greater than $90 \%$ [4].

Urine microscopy can be informative in particular clinical scenarios such as suspected poisoning. The presence of crystalluria may provide vital information and in the case of ethylene glycol poisoning oxalate crystals may be visible [5]. Patients who suffer from tumour lysis syndrome can produce urate crystal deposition. A number of drugs may lead to AKI and crystalluria including sulphonamides, acyclovir, triamterene, indinavir and cathartics high in phosphates.
Various measures have been claimed to aid in the diagnosis of AKI including urine osmolality, urine/ plasma creatinine and urea ratios, urinary sodium, fractional excretion of sodium $\left(\mathrm{FE}_{\mathrm{Na}}\right)$, fractional excretion of urea $\left(\mathrm{FE}_{\text {Urea }}\right)$, freewater clearance and creatinine clearance. All of these have limitations and their specificity and sensitivity in clinical practice often means that a single measurement may be inconclusive except in extreme circumstances [6-8].

In pre-renal AKI there is increased urinary sodium reabsorption and increased urinary urea reabsorption. This should therefore be reflected by low urine sodium concentrations, low $\mathrm{FE}_{\mathrm{Na}}$ and low $\mathrm{FE}_{\mathrm{Urea}}$, and increased blood urea:creatinine ratios.

Urinary electrolytes should be interpreted with caution, particularly in the elderly (who may already have an impaired concentrating ability), and in patients on diuretics or with a salt-losing state. In such patients the $\mathrm{FE}_{\text {Urea }}$ may possibly be a more useful index [8]. The normal $\mathrm{FE}_{\text {Urea }}$ is greater than $45 \%$. Levels of less than $35 \%$ are associated with pre-renal AKI. Patients with pre-renal AKI not on diuretics have both low $\mathrm{FE}_{\mathrm{Na}}$ $(<1 \%)$ and low $\mathrm{FE}_{\text {Urea }}$. However patients with prerenal AKI on diuretics have levels of $\mathrm{FE}_{\mathrm{Na}}$ greater than $2 \%$ but still have low levels of $\mathrm{FE}_{\text {Urea. }}$ In comparison, patients with ATN have both high $\mathrm{FE}_{\mathrm{Na}}$ and high $\mathrm{FE}_{\text {Urea. }}$.

One clinical situation where measurement of urinary electrolytes may have clinical utility is in the diagnosis of hepatorenal syndrome as the cause of AKI in patients with liver disease. The diagnostic criteria for hepatorenal failure include a urine sodium of less than $10 \mathrm{mmol} / \mathrm{L}$ (although not a major diagnostic criterion) [9].

Ultrasound is the gold standard test for diagnosis of upper tract obstruction through the finding of hydronephrosis and/or hydroureter. However upper urinary tract obstruction may not be initially detected by ultrasound in a patient who is volume depleted. It is therefore recommended to repeat the renal tract ultrasound if upper urinary tract obstruction is suspected once the patient is adequately fluid resuscitated.

There are other circumstances when ultrasound may not be diagnostic, such as in retroperitoneal fibrosis or early in the course of obstructive disease, in which case additional imaging studies may be considered such as dynamic nuclear medicine studies or CT. Dynamic nuclear medicine studies will be of little diagnostic use if the patient has oligo-anuric AKI. 


\section{References}

1 Liaño F, Pascual J and the Madrid Acute Renal Failure Study Group. Epidemiology of acute renal failure: a prospective, multicenter, communitybased study. Kidney International 1996;50:811-818

$\checkmark 2$ Lines S, Lewington A. Acute kidney injury. Clin Med. 2009 Jun;9[3]: 273-277

-3 Favaro S, Bonfant L, D’Angelo A, Giacomini A, Normanno M, Calo L. Is the red cell morphology really useful to detect the source of haematuria? Am J Nephrol 1997;17:172-175

4 Rossert J. Drug-induced acute interstitial nephritis. Kidney Int 2001; 60:804-817

5 Fogazzi GB. Crystalluria: a neglected aspect of urinary sediment analysis. Nephrol Dialysis Transplant 1996;11:379-387
Kellen M, Aronson S, Roizen MF, Barnard J, Thisted RA. Predictive and diagnostic tests of renal failure: A review. Anesth Analg 1994;78:134-142

7 Espinel CH, Gregory AW. Differential diagnosis of acute renal failure. Clin Nephrol 1980;13:73-77

8 Carvounis CP, Nisar S, Guro-Razuman S. Significance of the fractional excretion of urea in the differential diagnosis of acute renal failure. Kidney Int 2002;62:2223-2229

$\checkmark 9$ Arroyo V, Gines P, Gerbes AL et al. Definition and diagnostic criteria of refractory ascites and hepatorenal syndrome in cirrhosis. International Ascites Club Hepatology 1996;23:164-176 


\section{Acute Kidney Injury (AKI) (Guidelines AKI}

3.1-3.4)

Guideline 3.1 - AKI: Prevention; Risk Assessment

We recommend that patients at risk of AKI should be identified and appropriate preventative measures should be instituted as early as possible. (1B)

\section{Audit measures}

1. Incidence of acute admissions/patients undergoing major surgery who had

- risk of AKI assessed on admission/pre-surgery

- electrolytes checked on admission/pre-surgery and rechecked within 24 hours

2. Proportion of patients at risk of AKI who receive nephrotoxic medications

\section{Rationale}

Published series of AKI suggest that up to $30 \%$ of cases may be preventable, with a further significant percentage potentially remediable through simple interventions such as volume repletion, discontinuing and/or avoiding certain potentially nephrotoxic agents and earlier recognition of conditions causing rapid progression of AKI [1-3].

Risk factors for developing AKI include:

- age $>75$ yrs

- chronic kidney disease (CKD, eGFR $<60 \mathrm{mls} / \mathrm{min} /$ $1.73 \mathrm{~m}^{2}$ )

- cardiac failure

- atherosclerotic peripheral vascular disease

- liver disease

- diabetes mellitus

- nephrotoxic medication

- hypovolaemia

- sepsis

Guideline 3.2 - AKI: Prevention; Fluid Therapy

We recommend that prescription of appropriate intravenous fluid should be carefully considered following assessment of the patient's volume status. Thereafter the patient's clinical response should be monitored closely. (1B)

\section{Audit measure}

1. Proportion of patients at risk of AKI who are prescribed intravenous fluids without an assessment of volume status

\section{Rationale}

In hospital AKI following surgery is an important contributor to postoperative morbidity and mortality. The causes are multifactorial and therefore involve the identification of the high risk patients and institution of preventative measures. Avoidance of pre- and perioperative hypovolaemia is an essential component of patient management.

Prescription of intravenous fluid should follow a careful assessment of patient volume status i.e. hypovolaemic, euvolaemic, hypervolaemic. Consideration should then be made regarding the nature of the fluid lost and therefore the nature of the fluid that needs to be replaced. There is no evidence base to favour the prescription of crystalloid or colloids to protect kidney function in the peri-operative period, although there have only been a handful of studies looking at this [4]. Following the selection of the appropriate fluid the rate of fluid replacement must be guided by clinical assessment with consideration for safety limits. The patient's volume status must be continually monitored and a decision made regarding when to stop intravenous fluids.

It is important to recognise that the daily sodium intake in health is between 70 and $100 \mathrm{mmol} /$ day. Following surgery the body's physiological response is to retain sodium and water. The selection of the type of fluid to be prescribed is important as excessive peri-operative fluid therapy with $0.9 \%$ sodium chloride ( $\mathrm{Na} 154 \mathrm{mmol} / \mathrm{l}, \mathrm{Cl} 154 \mathrm{mmol} / \mathrm{l}$ ) can potentially lead to hyperchloraemic acidosis, sodium, chloride and water overload which contributes to postoperative morbidity and mortality [5] whereas excessive peri-operative fluid replacement with 5\% dextrose will increase the risk of developing hyponatraemia.

Fluid replacement prescriptions should be tailored to the needs of the patient. Potassium containing solutions (Hartmann's and Ringer's Lactate) should be used cautiously in patients who develop progressive AKI, due to the potential risk of exacerbating hyperkalaemia.

\section{Guideline 3.3 - AKI: Prevention; Contrast-Induced AKI (CI-AKI)}

We recommend that patients identified at being at risk of contrast induced-AKI (CI-AKI) should have a careful assessment of volume status and receive pre-procedure volume expansion with $0.9 \%$ sodium chloride or isotonic sodium bicarbonate if clinically indicated. (1A)

\section{Audit measure}

1. Proportion of patients at high risk of contrast induced AKI (CI-AKI) who developed AKI and did not 
- receive pre-procedure volume assessment

- receive appropriate volume expansion

- have appropriate adjustments to medications

\section{Rationale}

Contrast-induced acute kidney injury (CI-AKI) secondary to radiological contrast media is uncommon in the general population. It classically occurs within 72 hours of receiving the contrast media and usually recovers over the following five days. Its incidence increases significantly in patients with risk factors and is associated with an increased short and long-term mortality [6]. Acute kidney injury results from a combination of afferent arteriolar vasoconstriction and direct toxicity of the contrast media to the tubule epithelial cells.

Prevention is important as there is no specific treatment and involves the evaluation of potential risk factors (see guideline 3.1) and clinical assessment of the patient's volume status [7]. It should also be considered whether alternative imaging could be utilised such as magnetic resonance angiography or whether carbon dioxide can be used to reduce the amount of contrast agent required [8]. Patients identified as at high risk of CI-AKI should be discussed with a renal physician to assess the individual risk/benefit to the patient. It is recognised that in some patients the risk of CI-AKI is outweighed by the potential benefit from the contrast study.

Potentially nephrotoxic medications such as nonsteroidal anti-inflammatory drugs and aminoglycosides should be withheld or avoided. Currently there is insufficient evidence to support the routine discontinuation of angiotensin-converting enzyme inhibitors (ACE-I) or angiotensin receptor blockers (ARBs) in stable outpatients [9].

Metformin is not nephrotoxic but is exclusively excreted via the kidneys. Patients on metformin who develop AKI are at risk of developing lactic acidosis. The current advice from the Royal College of Radiologists is that there is no need to stop metformin after receiving contrast if the serum creatinine is within the normal range and/or eGFR $>60 \mathrm{ml} / \mathrm{min} / 1.73 \mathrm{~m}^{2}$. If serum creatinine is above the normal reference range or eGFR is $<60 \mathrm{ml} / \mathrm{min} / 1.73 \mathrm{~m}^{2}$, any decision to stop it for 48 hours should be made in consultation with the referring clinician [10].

Patients at risk of CI-AKI must receive appropriate volume expansion prior to the procedure. Intravenous $0.9 \%$ sodium chloride at a rate of $1 \mathrm{~mL} / \mathrm{kg} /$ hour for 12 hours pre- and post-procedure has been shown to be more effective than $0.45 \%$ sodium chloride in reducing CI-AKI [11]. More recently it has been demonstrated that intravenous isotonic sodium bicarbonate significantly reduces the risk of CI-AKI $[12,13]$. Subsequently there have been a number of studies that have compared intravenous isotonic sodium bicarbonate to intravenous $0.9 \%$ sodium chloride $[14,15]$. Systematic reviews and meta-analyses have provided conflicting conclusions and have recognised a significant degree of heterogeneity and publication bias. It is currently recommended that either intravenous $0.9 \%$ sodium chloride or isotonic sodium bicarbonate should be used for volume expansion in patients at risk of CI-AKI $[16,17]$.

It is generally accepted that high osmolar contrast media should be avoided in patients at risk of CI-AKI [18]. More controversial is the debate regarding whether iso-osmolar contrast media is safer than low-osmolar contrast media in patients at risk of CI-AKI. There have been a number of studies that have compared these two media and currently there is no clear benefit in preventing $\mathrm{CI}-\mathrm{AKI}$ in at risk patients by using isoosmolar contrast media in preference to low-osmolar contrast media [19].

The volume of contrast media should be minimised and further exposure to contrast media should be delayed until full recovery of renal function unless absolutely necessary [20]. Renal function should be checked up to 48-72 hours following the procedure in a high risk group to ensure stable renal function.

Following the seminal paper demonstrating the beneficial effects of $\mathrm{N}$-acetylcysteine in preventing CI-AKI there has been a multitude of publications which have been subject to a number of meta-analyses [21]. These metaanalyses have commented on the heterogeneity of the studies making a definitive conclusion difficult $[22,23]$. Currently there is no compelling evidence for the routine use of $\mathrm{N}$-acetylcysteine to prevent CI-AKI.

\section{Guideline 3.4 - AKI: Prevention; AKI secondary to Rhabdomyolysis}

We recommend that patients identified as being at risk of developing AKI secondary to rhabdomyolysis should receive intravenous volume expansion with $0.9 \%$ sodium chloride and sodium bicarbonate. (1B)

\section{Rationale}

Rhabdomyolysis induced AKI results from skeletal muscle injury and cell lysis with the release of myoglobin and other muscle breakdown products. Myoglobin is freely filtered by the kidneys and is directly toxic to the 
tubule epithelial cells particularly in the setting of hypovolaemia and acidosis. There are a number of causes including trauma, burns, compartment syndrome and drugs (cocaine, ecstasy, statins). Management includes volume assessment and close monitoring with aggressive fluid resuscitation and alkalinisation of the urine.

Fluid resuscitation with $0.9 \%$ sodium chloride is preferred at a rate of $10-15 \mathrm{ml} / \mathrm{kg} / \mathrm{hr}$ to achieve high urinary flow rates $(>100 \mathrm{ml} / \mathrm{hr})$, with the cautious addition of sodium bicarbonate $1.26 \%$ to maintain urinary $\mathrm{pH}>6.5$
[24]. Throughout this process the patient's volume status must be carefully evaluated and once the patient has been adequately fluid resuscitated care must be taken not to precipitate pulmonary oedema.

Mannitol is still used because of its properties as an osmotic diuretic and free radical scavenger by many centres although there is little clinical data to support its use [25]. Inappropriate use of mannitol can precipitate pulmonary oedema particularly if used with hypertonic sodium bicarbonate.

\section{References}

$\checkmark 1$ Stevens PE, Tamimi NA, Al Hasani MK et al. Non-specialist management of acute renal failure. QJM 2001;94:533-540

$\checkmark 2$ Vijayan A, Miller SB. Acute renal failure: prevention and nondialytic therapy. Semin Nephrol 1998;18:523-532

$\checkmark 3$ Davidman M, Olson P, Kohen J, Leither T, Kjellstrand C. Iatrogenic renal disease. Arch Intern Med 1991;151:1809-1812

4 Zacharias M, Gilmore ICS, Herbison GP et al. Interventions for protecting renal function in the perioperative period (Review). Cochrane Database of Systematic Reviews 2005; Issue 3:CD003590

$\checkmark 5$ Lobo DN, Macafee DAL, Allison SP. How perioperative fluid balance influences post-operative outcomes. Best Practice and Research Clinical Anaesthesiology 2006;20[3];439-455

6 Levy EM, Viscoli CM, Horwitz RI. The effect of acute renal failure on mortality: a cohort analysis. JAMA 1996;275:1489-1494

7 Stacul F, Adam A, Becker CR, et al. Strategies to reduce the risk of contrast-induced nephropathy. Am J Cardiol 2006;98, 59K-77K

$\checkmark 8$ Shaw DR, Kessel DO. The current status of the use of carbon dioxide in diagnostic and interventional angiographic procedures. Cardiovasc Intervent Radiol 2006;29:323-331

9 Rosenstock JL, Bruno R, Kim JK, Lubarsky L, Schaller R, Panagopoulos G, DeVita MV, Michelis MF. The effect of withdrawal of ACE inhibitors or angiotensin receptor blockers prior to coronary angiography on the incidence of contrast-induced nephropathy. Int Urol Nephrol. 2008; 40[3]:749-755

10 Metformin: updated guidance for use in diabetics with renal impairment. London: The Royal College of Radiologists www.RCR.ac.uk 2009

-11 Mueller C, Buerkle G, Buettner HJ, et al. Prevention of contrast media associated nephropathy: randomised comparison of 2 hydration regimens in 1620 patients undergoing coronary angioplasty. Arch Intern Med 2002;162:329-336

-12 Merten GJ, Burgess WP, Gray LV, et al. Prevention of contrast induced nephropathy with sodium bicarbonate: a randomized controlled trial. JAMA 2004;291:2328-2334

13 Zoungas S, Ninomiya T, Huxley R, Cass A, Jardine M, Gallagher M, Patel A, Vasheghani-Farahani A, Sadigh G, Perkovic V. Systematic review: sodium bicarbonate treatment regimens for the prevention of contrast-induced nephropathy. Ann Intern Med. 2009 Nov 3;151[9]: 631-638

14 Adolph E, Holdt-Lehmann B, Chatterjee T, Paschka S, Prott A, Schneider H, Koerber T, Ince H, Steiner M, Schuff-Werner P, Nienaber CA. Renal Insufficiency Following Radiocontrast Exposure Trial (REINFORCE): a randomized comparison of sodium bicarbonate versus sodium chloride hydration for the prevention of contrastinduced nephropathy. Coron Artery Dis. 2008 Sep;19[6]:413-419

15 Ozcan EE, Guneri S, Akdeniz B, Akyildiz IZ, Senaslan O, Baris N, Aslan $\mathrm{O}$, Badak O. Sodium bicarbonate, $\mathrm{N}$-acetylcysteine, and saline for prevention of radiocontrast-induced nephropathy. A comparison of 3 regimens for protecting contrast-induced nephropathy in patients undergoing coronary procedures. A single-center prospective controlled trial. Am Heart J. 2007 Sep;154[3]:539-544

- 16 Hoste EA, De Waele JJ, Gevaert SA, Uchino S, Kellum JA. Sodium bicarbonate for prevention of contrast-induced acute kidney injury: a systematic review and meta-analysis. Nephrol Dial Transplant. 2010 Mar;25[3]:747-758

17 Brar SS, Hiremath S, Dangas G, Mehran R, Brar SK, Leon MB. Sodium bicarbonate for the prevention of contrast induced-acute kidney injury: a systematic review and meta-analysis. Clin J Am Soc Nephrol. 2009 Oct;4[10]:1584-1592

18 Barrett BJ, Carlisle EJ. Meta-analysis of the relative nephrotoxicity of high-and low-osmolality iodinated contrast media. Radiology 1993; 188:171-178

19 Heinrich MC, Häberle L, Müller V, Bautz W, Uder M. Nephrotoxicity of iso-osmolar iodixanol compared with nonionic low-osmolar contrast media: meta-analysis of randomized controlled trials. Radiology. 2009 Jan;250[1]:68-86

20 Cigarroa RG, Lange RA, Williams RH, Hillis LD. Dosing of contrast material to prevent contrast nephropathy in patients with renal disease. Am J Med. 1989 Jun;86(6 Pt 1):649-652

21 Tepel M, van der Giet M, Schwarzfeld C, Laufer U, Liermann D, Zidek W. Prevention of radiographic-contrast-agent-induced reductions in renal function by acetylcysteine. N Engl J Med. 2000 Jul 20;343[3]: $180-184$

22 Kshirsagar AV, Poole C, Mottl A et al. N-acetylsysteine for the prevention of radio contrast induced nephropathy: a meta-analysis of prospective controlled trials. J Am Soc Nephrol 2004;15:761-769

23 Nallamothu BK, Shojania KG, Saint et al. Is N-acetylsysteine effective in preventing contrast-related nephropathy? A meta-analysis. Am J Med 2004;117:938-947

24 Sever MS, Vanholder R, Lameire N. Management of crush related injuries after disasters. N Eng J Med 2006;354:1052-1063

25 Brown CVR, Rhee P, Chan L et al. Preventing renal failure in patients with rhabdomyolysis: do bicarbonate and mannitol make a difference? J Trauma 2004;56:1191-1196 


\section{Acute Kidney Injury (AKI) (Guidelines AKI} 4.1-4.5)

\section{Guideline 4.1 - AKI: Management; General Management}

We recommend that general supportive measures include optimisation of haemodynamic status by appropriate fluid therapy, administration of vasopressors and/or inotropes and treatment of any underlying sepsis. Nephrotoxic medications should be stopped. (1A)

\section{Audit measures}

1. Proportion of patients with AKI who are prescribed intravenous fluids without an assessment of volume status

2. Proportion of patients with AKI who receive nephrotoxic medications

3. Proportion of patients with severe AKI where there is documented evidence of patient involvement in decision making with respect to commencing renal replacement therapy (RRT)

4. Proportion of AKI survivors who are given information on the cause of AKI and how this might be avoided in the future

\section{Rationale}

In the majority of cases AKI can be effectively treated and resolved by adequate volume replacement, treatment of the underlying medical condition (e.g. sepsis, haemorrhage) and avoidance of nephrotoxic medications. However it is important to remember that the more esoteric forms of AKI will require specific therapy which is outside of the remit of this guideline.

In the hypovolaemic patient fluid replacement is best achieved through the rapid infusion of repeated small volumes $(250 \mathrm{ml}$ of crystalloid or colloid) and close monitoring using a CVP line and urinary tract catheter (if clinically indicated, as its use is associated with an increased risk of infection)). Lactate and base excess measurements may also be helpful in conjunction with clinical judgment in assessing response to volume loading [1].

With respect to the use of colloids it should be acknowledged that there have been earlier reports regarding the use of high molecular weight hydroxy ethyl starch and an increased risk of AKI $[2,3]$. The multi-centre German trial, Efficacy of Volume Substitution and Insulin Therapy in Severe Sepsis Trial (VISEP), reported a significantly higher incidence of AKI in patients receiving 10\% hydroxyethyl starch compared to Ringer's lactate $[4,5]$. It is therefore probably prudent to recommend that high molecular weight hydroxyethyl starches be used cautiously in patients with severe sepsis at risk of developing AKI. The French equivalent of the UK Blood Transfusion service recommends an upper limit on the volume of starch solutions used in resuscitation of patients [6]. A large well controlled prospective study is needed to conclusively prove the safety of administering hydroxyethyl starch on a daily basis in this patient group.

A decreasing urine output is a sensitive indicator of AKI and oliguric AKI is associated with a poorer prognosis. Documentation of urine volume is part of fluid balance management in any acutely ill patient. However there are a number of caveats to consider. Urine volume may not be diagnostic, particularly when diuretics have already been administered. It must also be recognised that part of the usual stress response to surgery is an increased secretion of antidiuretic hormone $(\mathrm{ADH})$ and an upregulation of the renin-angiotensin-aldosterone system resulting in avid salt and water retention [7]. As a consequence there is decreased urine output and free water clearance in the first 12-24 hours following surgery [8]. A careful evalution of volume status is required and not necessarily the prescription of more fluid. If the patient is not hypovolaemic there is evidence that demonstrates there is no association between urine output per se and the development of AKI [9].

In patients with severe AKI there may be no other option than to commence renal replacement therapy (RRT). Such decisions should be discussed with the patient if they have mental capacity. The NCEPOD adding insult to injury report detected a concerning lack of such discussions with patients or relatives documented in the notes. The commonly accepted indications for commencing RRT are listed in Table 3, section 11.

It is important to monitor the patient's volume status throughout the episode of AKI. This remains an essential part of patient management in the recovery phase. Patients may develop a polyuric phase during which they are at increased risk of developing a negative fluid balance and electrolyte disturbance including hypernatraemia and hypokalaemia. There will need to be careful consideration of when to reintroduce medications such as antihypertensives and diuretics. Unfortunately this can be overlooked placing the patient at risk of future readmission.

Following an episode of AKI the patient should receive information regarding the cause and how this may be potentially avoided in the future. This may involve educating and empowering the patient with respect to 
their risk factors for developing AKI and advice as to when to consider contacting their general practitioner in the future if they develop intercurrent illness in the community.

Guideline 4.2 - AKI: Management; Pharmacological Therapy

We recommend that therapeutic drug dosing must be adapted to altered kinetics in AKI. (1B)

\section{Audit measure}

1. Proportion of patients with AKI who did not have the appropriate adjustment of medication doses

\section{Rationale}

Inappropriate drug dosing of patients with $\mathrm{AKI}$ is an important cause of adverse drug events [10]. Pharmacokinetics including the volume of distribution, clearance and protein binding are altered by organ failure in the critically ill patient. Drug doses need to be adjusted appropriately with the correct assessment of kidney function to reduce toxicity. There is an important role for the clinical pharmacist on the ICU. A number of publications have demonstrated the clinical and economic benefits of the critical care pharmacist [11].

Guideline 4.3 - AKI: Management; Pharmacological Therapy

We recommend that there is no specific pharmacological therapy proven to effectively treat AKI secondary to hypoperfusion injury and/or sepsis. (1B)

\section{Rationale}

There is currently no evidence to support the use of a specific pharmacological therapy in the treatment of AKI secondary to hypoperfusion injury and/or sepsis. The rationale behind the use of loop diuretics was based on their putative ability to reduce the energy requirements of the cells of the ascending limb of Henle and therefore ameliorate the resultant ischaemic damage [12]. Loop diuretics have also been used to convert patients with oliguric AKI to non-oliguric AKI (recognised to have a better prognosis), to facilitate the management of fluid and electrolyte disturbances and reduce the requirement for renal replacement therapy (RRT). Of concern has been the demonstration that the use of loop diuretics is associated with an increased risk of failure to recover renal function and mortality, perhaps related to the resultant delay in commencing RRT appropriately [13]. A recent meta-analysis of nine randomised controlled trials concluded that furosemide is not associated with any significant clinical benefits in the prevention and treatment of AKI in adults [14]. High doses can be associated with an increased risk of ototoxicity which is an important consideration particularly in those patients ventilated on the ICU.

Dopamine is a non-selective dopamine receptor agonist which at low-dose $(0.5-3.0 \mu \mathrm{g} / \mathrm{kg} / \mathrm{min})$ induces a dose-dependent increase in renal blood flow, natriuresis and diuresis in healthy humans [15]. It has been proposed that dopamine may potentially reduce ischaemic cell injury in patients with AKI by improving renal blood flow and reducing oxygen consumption through inhibition of sodium transport. There have been a multitude of studies investigating the use of dopamine in the prevention and treatment of AKI which were most recently reviewed in a meta-analysis that concluded that there is no good evidence to support any important clinical benefits to patients with or at risk of AKI [16]. A possible explanation as to why dopamine is not beneficial has been provided by a study demonstrating that lowdose dopamine can worsen renal perfusion in patients with AKI [17]. Additionally the use of dopamine is associated with side-effects which include cardiac arrhythmias and myocardial and intestinal ischaemia [18].

Fenoldopam, in contrast to dopamine is a selective dopamine A-1 receptor agonist which decreases systemic vascular resistance whilst increasing renal blood flow to both the cortex and medullary regions in the kidney [19]. It has been used in patients with hypertensive emergencies [20] and has been noted to improve renal function in patients with severe hypertension [21]. The majority of small clinical studies that have been performed to date have investigated fenoldopam's ability to prevent the development of AKI without providing conclusive evidence. A beneficial effect of fenoldopam in critically ill patients with or at risk of AKI has been suggested by a meta-analysis of 16 randomised studies [22]. The meta-analysis concluded that fenoldopam reduces the need for renal replacement therapy and mortality in patients with AKI. Such results highlight the need for large multicentre randomised controlled trials to be performed before the use of fenoldopam can be recommended.

\section{Guideline 4.4 - AKI: Management; Nutritional Support}

We recommend that patients with AKI receiving renal replacement therapy should be referred to a dietician for individual assessment. (1D) 


\section{Guideline 4.5 - AKI: Management; Nutritional support}

We recommend that patients with AKI should receive $25-35 \mathrm{kcal} / \mathrm{kg} /$ day and up to a maximum of $1.7 \mathrm{~g}$ amino acids $/ \mathrm{kg} /$ day if hypercatabolic and receiving continuous renal replacement therapy. Trace elements and water soluble vitamins should be supplemented as required. (1C)

\section{Audit measures}

1. Proportion of patients with AKI receiving renal replacement therapy reviewed by dietician within 24 hours

2. Proportion of patients with AKI receiving renal replacement therapy prescribed the recommended nutritional support

\section{Rationale for 4.4 and 4.5}

Malnutrition has been identified as a predictor of in-hospital mortality for patients with AKI independent of complications and co-morbidities [23]. AKI is associated with significant metabolic and immunologic disturbances along with the induction of a pro-inflammatory state which is exacerbated by malnutrition [24]. Appropriate nutritional support could potentially mitigate these disturbances and improve outcomes. However very few systematic studies have been performed assessing the impact of nutrition on recognised clinical endpoints. Recommendations are therefore based on expert opinion.

AKI results in perturbations of fluid, electrolyte and acid base metabolism in association with specific alterations in protein and amino acid, carbohydrate and lipid metabolism. Negative nitrogen balance results from protein catabolism and the release of amino acids from skeletal muscle [25]. Hyperglycaemia may occur due to insulin resistance [26], decreased glucose uptake by skeletal muscle and accelerated hepatic gluconeogenesis [27]. Impaired lipolysis is the major contributor to lipid abnormalities including hypertriglyceridaemia [28].

Another consequence of AKI is disruption of vitamin and trace element balance. Levels of water-soluble vitamins are usually low with the exception of vitamin C. It is therefore important to avoid inappropriate supplementation of vitamin $\mathrm{C}$ due to the risk of developing secondary oxalosis. The levels of fat soluble vitamins A and $\mathrm{E}$ are reduced, whilst vitamin $\mathrm{K}$ levels are normal or even elevated. The trace element selenium has been shown to be profoundly decreased in patients with AKI [29].

Nutritional support for patients with AKI must take into account not only the specific metabolic disturbances associated with the kidney injury but also the underlying disease process. It is recognised that patients with AKI represent a heterogeneous group rarely presenting with an isolated disease process but often in association with sepsis and multi-organ failure.

Renal replacement therapy results in loss of both macronutrients and micronutrients which must therefore be supplemented. The impact made by RRT depends on the method utilised and its intensity. Continuous renal replacement therapy (CRRT) results in significant loss of water-soluble, small molecular weight substances including nutrients. A total daily loss of 10-15 g amino acids and 5-10g protein has been reported along with significant losses of water-soluble vitamins [30].

Enteral nutrition is the recommended form of nutritional support for patients with AKI. The provision of nutrients via the gut lumen helps maintain gut integrity, decreases gut atrophy and decreases bacterial and endotoxin translocation. If oral feeding is not possible then enteral feeding (tube feeding) should be initiated within 24 hours, which has been shown to be safe and effective [31]. A nasogastric tube is recognised as the standard access for administration of enteral nutrition. However a jejunal tube may be indicated in the presence of impaired gastrointestinal motility.

Total parenteral nutrition should be considered to supplement the enteral route or in those patients without a functioning gut. Referral to a dietician for individual assessment is recommended as nutrient requirements for patients will vary considerably dependent upon the course of the AKI, underlying disease and need for RRT [32].

Guidelines on enteral nutrition in patients with AKI have been developed by an interdisciplinary expert group and published by the European Society for Clinical Nutrition and Metabolism Patients [33]. Nutritional requirements are dependent upon the severity of the underlying disease and the type and intensity of RRT. As a general rule patients with AKI should receive $20-35 \mathrm{kcal} / \mathrm{kg} /$ day and up to a maximum of $1.7 \mathrm{~g}$ amino acids/kg/day if hypercatabolic and receiving CRRT. Electrolytes must be monitored closely to avoid hypokalaemia and/or hypophosphataemia following the initiation of enteral nutrition. 


\section{References}

1 Pinsky MR et al. Fluid and volume monitoring. Int J Artif Organs 2008;31:111-126

$\checkmark 2$ Schortgen F et al. Effects of hydroxyethyl starch and gelatin on renal function in severe sepsis: a multicentre randomised study. Lancet 2001;357:911-916

3 Cittanova ML et al. Effects of hydroxy ethyl starch in brain-dead kidney donors on renal function in a kidney transplant recipients. Lancet 1996;348:1620-1622

$\checkmark 4$ Bagshaw S, et al. Fluid resuscitation and the septic kidney. Current Opinions in Critical Care 2006;12:527-530

$\checkmark 5$ Brunkhorst et al. German Competence Network Sepsis (SepNet). Intensive insulin therapy and pentastarch resuscitation in severe sepsis. $\mathrm{N}$ Engl J Med. 2008;358:125-139

$\checkmark 6$ Schortgen $\mathrm{F}$ et al. Effects of hydroxyethylstarch and gelatin on renal function in severe sepsis: a multicentre randomised study. Lancet 2001;357:911-916

7 Lobo DN, Macafee DAL, Allison SP. How perioperative fluid balance influences post-operative outcomes. Best Practice and Research Clinical Anaesthesiology 2006;20[3]:439-455

8 Gann DS, Kenney PR. Special problems of fluid and electrolyte management in surgery. Chan JCM and Gill JR eds, Kidney Electrolyte Disorders. Churchill Livingstone Inc USA 1990;343-362

$\checkmark 9$ Alpert RA, Roizen MF, Hamilton WK et al. Intraoperative Urinary Output Does Not Predict Postoperative Renal Function in Patients Undergoing Abdominal Aortic Revascularisation. Surgery 1984;95: 707-711

10 Schiff GD, Klass D, Peterson J et al. Linking laboratory and pharmacy: opportunities for reducing errors and improving care. Arch Intern Med 2003;163:893-900

-11 Kane SL, Weber RJ, Dasta JF. The impact of critical care pharmacists on enhancing patient outcomes. Intensive Care Med 2003;29:691-698

-12 Heyman SN, Rosen S, Epstein FH et al. Loop diuretics reduce hypoxic damage to proximal tubules of the isolated perfused rat kidney. Kidney Int 1994;45:981-985

13 Mehta RL, Pascual MT, Soroko S et al. Diuretics, mortality, and nonrecovery of renal function in acute renal failure. JAMA 2002;288: 2547-2553

14 Ho KM, Sheridan DJ. Meta-analysis of frusemide to prevent or treat acute renal failure. BMJ 2006;333(7565):420-425

$\checkmark 15$ Denton MD, Chertow GM, Brady HR. Renal-dose dopamine for the treatment of acute renal failure: scientific rationale, experimental studies and clinical trials. Kidney Int 1996;49:4-14

-16 Friedrich JO, Adhikari N, Herridge MS. Meta-analysis: low-dose dopamine increases urine output but does not prevent renal dysfunction or death. Ann Intern Med 2005;142:510-524
17 Lauschke A, Teichgraber UKM, Frei U et al. Low-dose dopamine worsens renal perfusion in patients with acute renal failure. Kidney Int 2006;69:1669-1674

18 Schenarts PA, Sagraves SG, Bard M et al. Low-dose dopamine: a physiologically based review. Current Surgery 2006;63 [3]:219-225

19 Mathur VS, Swan SK, Lambrecht LJ et al. The effects of fenoldapam, a selective dopamine receptor agonist, on systemic and renal haemodynamics in normotensive subjects. Crit Care Med 1999;29:1832-1837

20 Murphy MB, Murray C, Shorten GD. Fenoldapam: a selective peripheral dopamine receptor agonist for the treatment of severe hypertension. $\mathrm{N}$ Engl J Med 2001;345:1548-1557

21 Schusterman NH, Elliott WJ, White WB. Fenoldapam, but not nitroprusside, improves renal function in severely hypertensive patients with impaired renal function. Am J Med 1993;95:161-168

22 Landoni G, Biondi-Zoccai GGL, Tumlin JA et al. Beneficial impact of fenoldapam in critically ill patients with or at risk for acute renal failure: a meta-analysis of randomised clinical trials. Am J Kidney Dis 2007; 49[1]:56-68

23 Fiaccadori E, Lombardi M, Leonardi S, Rotelli CF, Tortorella G, Borghetti A. Prevalence and clinical outcome associated with preexisting malnutrition in acute renal failure: a prospective cohort study. J Am Soc Nephrol 1999;10:581-593

24 Druml W. Nutritional management of acute renal failure. J Renal Nutrition 2005; 15:63-70

25 Druml W. Protein metabolism in acute renal failure. Miner Electrolyte Metab 1998;24:47-54

26 May RC, Clark AS, Goheer MA et al. Specific defects in insulin mediated muscle metabolism in acute uraemia. Kidney Int 1985;28:490-497

27 Cianciaruso B, Bellizzi V, Napoli R et al. Hepatic uptake and release of glucose, lactate, and amino acids in acutely uraemic dogs. Metabolism 1991;40:261-269

28 Druml W, Zechner R, Magometschnigg D et al. Post heparin lipolytic activity in acute renal failure. Clin Nephrol 1985;23:289-293

29 Metnitz GH, Fischer M, Bartens C et al. Impact of acute renal failure on antioxidant status in multiple organ failure. Acta Anaesthesiol Scand 2000;44:236-240

30 Bellomo R, Martin H, Parkin G et al. Continuous arteriovenous haemodiafiltration in the critically ill: influence on major nutrient balances. Intensive Care Med 1991;17:399-402

31 Fiaccadori E, Maggiore U, Giacosa R et al. Enteral nutrition in patients with acute renal failure. Kidney Int 2004;65:999-1008

32 Kreymann KG, Berger MM, Deutz NEP et al. ESPEN guidelines on enteral nutrition: intensive care. Clin Nutrition 2006;25:210-223

$\checkmark 33$ Cano N, Fiaccadori E, Tesinsky P et al. ESPEN guidelines on enteral nutrition: adult renal failure. Clin Nutrition 2006;25:295-310 


\section{Acute Kidney Injury (AKI) (Guidelines AKI} 5.1-5.7)

\section{Guideline 5.1 - AKI: Treatment facilities and referral} to renal services

We recommend that renal services should work together with other specialties to develop guidelines for the management of AKI. These should include clear guidelines with respect to when to request a renal referral. (1A)

\section{Guideline 5.2 - AKI: Treatment facilities and referral} to renal services

We recommend that specialist renal advice should be given with consultant renal physician input. (1B)

\section{Guideline 5.3-AKI: Treatment facilities and referral to renal services}

We recommend that transfer protocols should be developed based on local physiological early warning scores to ensure appropriate triage of in-patients with AKI arriving from other hospitals. (1C)

Guideline 5.4 - AKI: Treatment facilities and referral to renal services

We recommend that physiological surveillance should be performed for all patients with AKI to identify early signs of physiological deterioration which may require escalation in the level of care. (1A)

\section{Guideline 5.5 - AKI: Treatment facilities and referral} to renal services

We suggest that renal physicians and intensivists should work together to provide care for patients with AKI on the intensive care unit (ICU). Nephrology trainees should be trained to care for acutely ill patients with AKI. (2C)

\section{Guideline 5.6-AKI: Treatment facilities and referral} to renal services

We suggest that intensive care units should contact renal services to discuss patients likely to require ongoing single organ renal support prior to step-down. Advance warning of such patients will facilitate forward planning and continued follow-up. (2C)

\section{Guideline 5.7-AKI: Treatment facilities and referral} to renal services

We recommend that AKI survivors with residual renal impairment should be managed according to local chronic kidney disease (CKD) guidelines. Discharge planning should include plans for CKD management, where relevant. (1A)

\section{Audit measures}

1. Incidence of delays of transfer of patients with AKI $>24$ hours following referral to renal services due to a lack of resources on renal unit

2. Incidence of patients with single organ AKI admitted to ICU for RRT due to a lack of resources on the renal unit

3. Number of AKI in-patient transfers requiring escalation of care within 24 hours of arrival on renal unit

4. Proportion of AKI survivors with residual chronic kidney disease with post-discharge CKD planning

\section{Rationale for 5.1-5.7}

Almost all AKI develops outside of the renal unit and it should be possible to manage the majority of patients either in the non-specialist ward or in critical care areas. The most appropriate facility for care will depend on the presence or absence of non-renal organ failure, the need for renal support and the need for renal specialist input. The latter will be determined, in part, by the likelihood that AKI will be transient and self-limiting, and by the aetiology of AKI - particularly if an esoteric diagnosis is possible [1].

There are three, key interfaces which may well be geographically remote but whose smooth function will help determine the most appropriate venue for management. These exist between the non-specialist ward and critical care (critical care outreach), between renal services and critical care (the critical care/nephrology interface) and between renal services and the non-specialist ward (acute renal outreach). Organisation of these interfaces will be dictated by local geography, practice and resource. The need for clarity in these interactions has been highlighted by a range of studies that have suggested both clinical and organisational deficiencies in management.

Shortfalls in the basics of initial assessment and management on non-specialist wards have been well demonstrated in both regional [2] and national studies [3]. In those who might need it, referral for a renal specialist opinion may be delayed $[3,4]$ or not even undertaken [3,5]. These deficiencies, coupled with failures in the timely recognition of the acutely ill patient and the need to escalate care [3], may place unnecessary pressure on critical care and renal services from pathology that might, otherwise, have been mitigated. 
Care of the AKI patient on non-specialist wards may be facilitated in two ways. The first is through the use of physiological severity scores to aid the recognition, management and placement of the acutely ill patient. These should now be established in routine practice [6]. The second is by enhancing the initial assessment and treatment of evolving AKI [1] to both optimise the management of those who could remain in that non-specialist area, and also, for those who need it, ensure timely transfer to renal services. How this goal might be achieved is unclear but a suggested solution may include the development and dissemination of clear, written guidelines. A supplementary educational package may be of benefit. Both non-specialists and renal services should have an understanding of the indications for seeking specialist renal advice and of transfer and treatment protocols. Renal advice should be provided with consultant input given the evidence that this can be poor when offered at a more junior level [3]. Mechanisms to monitor and assure success have yet to be established but could include longitudinal audit of the incidence of severe AKI, augmented by root cause analysis.

Most AKI managed in critical care areas is parochial in origin [7] and usually associated with other organ dysfunction. Nevertheless, vigilance needs to be maintained for those causes that may be esoteric and require specialist renal input. This may be especially relevant for those ICUs who cannot call upon bedside nephrological assessment (around one third in a recent survey [8]). The main interaction between renal services and critical care will, however, be the flow of sick ESRD patients in one direction [9] and the reciprocal stepdown of AKI patients still requiring single organ, renal support. The latter may represent a specific bottleneck in patient flow due to renal capacity constraints and widening provision of RRT on ICU, with $43 \%$ having no on-site step-down facility of any nature on which renal support can continue [8].

Although evidence for delayed step-down from critical care was found in a short, observational survey of severe, single-organ AKI in Greater Manchester [4], a 12 month survey of patient flow across the North East and Cumbria Critical Care Network showed that such delays were relatively short (median 2 days) and amounted to a relatively modest number of critical care bed days consumed (113 in that year) [9]. The study found that the period of single organ renal support was significantly longer on those ICUs without a renal unit on site but the results, overall, did not support the anecdotal impression of frequently delayed step-down of these patients. It is recommended, nevertheless, that early contact is made with renal services to allow forward planning for those patients likely to step-down still requiring renal support.

The UK Department of Health (DH) has recommended that patients with single organ failure requiring observation or intervention should receive level 2 (high dependency unit, HDU) care [10]. A failure to do so may place undue pressure on level 3 facilities and, furthermore, may increase mortality [11]. DH recommendations would clearly include AKI but a pragmatic interpretation would limit the scope to the more severe (AKIN stage 3) cases. In addition, although many renal units do contain level 2 facilities, diversion of patients away from those that do not is not only impractical but, we feel, is also disadvantageous when renal, not critical, care is required. Such units must, however, maintain physiological surveillance of AKI patients under their care and clear pathways should be established to allow rapid escalation of care for those that are deteriorating.

Although timely renal transfer may be a key goal, the arrival of patients on the renal unit with unheralded critical illness is a potential disaster in terms of both safety and the unexpected burden that this might place on local critical care services. A prospective, single centre observational study examined the utility of the SOFA (Sequential Organ Failure Assessment) score as a predictor of later escalation of care in AKI patients transferring from outside hospitals [12]. Those requiring escalation of care within the first 24 hours after transfer had high scores. The tool could not determine the most appropriate venue for transfer but might augment subjective assessment of illness severity by the referring team, trigger pre-emptive responses by the receiving team, such as early liaison with critical care, and warn of the need for more frequent physiological observation after arrival on the renal unit. The local MEWS (Modified Early Warning System) score seems to have similar utility to the SOFA score but has the added advantage of harmonising with physiological assessment within the receiving institution, as a whole (unpublished data, N.S. Kanagasundaram).

A further consideration for AKI survivors is the long term management of persisting renal dysfunction after hospital discharge. A recent observational study of survivors of AKI requiring renal support found incomplete recovery of renal function to be an independent determinant of long term survival [13] in keeping with the role of $\mathrm{CKD}$ as an independent risk factor for 
death. A subsequent observational study of survivors of RRT-requiring ICU AKI confirmed these findings [14]; patients with de novo CKD following AKI had poorer long term survival than those with full recovery of renal function although the highest post-discharge mortality was in survivors with CKD that had pre-dated AKI. Ten per cent of these survivors to hospital discharge eventually reached ESRD with those with pre-existing CKD seeming to be at highest risk.

\section{References}

$>1$ Hussein HK, Lewington AJP, Kanagasundaram NS. General management of acute kidney injury. British Journal of Hospital Medicine 2009;70:M104-M107

2 Stevens PE, Tamimi NA, Al-Hasani MK, Mikhail AI, Kearney E, Lapworth R, Prosser DI, Carmichael P. Non-specialist management of acute renal failure. QJM 2001;94:533-540

3 Stewart J, Findlay G, Smith N, Kelly K, Mason M. Adding insult to injury: A review of the care of patients who died in hospital with a primary diagnosis of acute kidney injury (acute renal failure). London, National Confidential Enquiry into Patient Outcome and Death, 2009

4 Hegarty J, Middleton RJ, Krebs M, Hussain H, Cheung C, Ledson T, Hutchison AJ, Kalra PA, Rayner HC, Stevens PE, O’Donoghue DJ. Severe acute renal failure in adults: Place of care, incidence and outcomes. QJM 2005;98:661-666. Epub 2005 Jul 2029

$\checkmark 5$ Feest TG, Round A, Hamad S. Incidence of severe acute renal failure in adults: Results of a community based study. Br Med J 1993;306: 481-483

6 Armitage M, Eddleston J, Stokes T on behalf of the Guideline Development Group. Recognising and responding to acute illness in adults in hospital: Summary of NICE guidance. BMJ 2007;335:258-259

7 Liano F, Junco E, Pascual J, Madero R, Verde E. The spectrum of acute renal failure in the intensive care unit compared with that seen
The burden of CKD in survivors of AKI and the numbers progressing to ESRD may be under-appreciated. Planning for long term management of persisting CKD may be particularly poor for those patients residing on non-renal wards who have been discharged from followup by the acute renal outreach service (unpublished data, N.S. Kanagasundaram). There is a need for AKI survivors to have a clear post-discharge plan for follow-up and management of residual renal dysfunction, if present.

in other settings. The Madrid acute renal failure study group. Kidney International 1998;53:S16-S24

${ }_{8}$ Wright SE, Bodenham A, Short AI, Turney JH. The provision and practice of renal replacement therapy on adult intensive care units in the United Kingdom. Anaesthesia 2003;58:1063-1069

$\checkmark 9$ Wright SE, Baudouin SV, Kaudeer N, Shrestha S, Malone J, Burn L, Kanagasundaram NS. Patient flow from critical care to renal services: A year-long survey in a critical care network. QJM 2008;101:643-648

10 Anonymous: Comprehensive critical care: A review of adult services in UK (ed. London, Department of Health UK, 2000)

11 Lyons RA, Wareham K, Hutchings HA, Major E, Ferguson B. Population requirement for adult critical-care beds: A prospective quantitative and qualitative study. Lancet 2000;355:595-598

-12 Kanagasundaram NS, Jones KE. Transfer of patients with acute kidney injury to specialist renal services - physiological early-warning systems, applied prior to transfer from outside hospitals, can identify those at risk of deterioration. QJM 2008;101:249-250

13 Schiffl H, Fischer R. Five-year outcomes of severe acute kidney injury requiring renal replacement therapy. Nephrology Dialysis Transplantation 2008;23:2235-2241

14 Triverio P-A, Martin P-Y, Romand J, Pugin J, Perneger T, Saudan P. Long-term prognosis after acute kidney injury requiring renal replacement therapy. Nephrol Dial Transplant 2009;24:2186-2189 


\section{Acute Kidney Injury (AKI) (Guideline AKI 6.1)}

\section{Guideline 6.1 - AKI: Choice of renal replacement therapy modality}

We recommend that the choice of renal replacement therapy modality should be guided by the individual patient's clinical status, medical and nursing expertise, and availability of modality. (1B)

\section{Rationale}

Analysis of the current literature does not allow evidence-based guidelines for the selection of RRT modality for the treatment of AKI. In the early 1980s the options for RRT therapy were generally limited to intermittent haemodialysis (IHD) and peritoneal dialysis (PD). The currently available therapies in industrialised societies now include various forms of continuous renal replacement therapy (CRRT) and newer 'hybrid' therapies such as extended duration dialysis (EDD), sustained low-efficiency dialysis (SLED) and the Genius ${ }^{\circledR}$ system. Despite the increasing technological sophistication of RRT, key clinical management issues such as the optimal dosing of therapy and whether the selection of treatment modality impact on patient and renal survival remain to be determined.

Although it is widely perceived that CRRT is superior to IHD in haemodynamically unstable critically ill patients, prospective randomised clinical trials have failed to confirm this supposition. In many of the earlier trials there was a bias for the more critically ill patients to receive CRRT rather than IHD. For example, Swartz and colleagues [1] retrospectively compared patients treated with CVVH or IHD and reported a two-fold greater mortality in patients treated with CVVH. However after adjusting for severity of illness, there was no difference. Similarly, in a prospective study, mortality was $79 \%$ in patients treated with CRRT compared to $59 \%$ in the IHD treated group, but after adjustment for co-morbidities, the modality of RRT was no longer a risk factor for outcome [2].

Six randomised prospective controlled trials comparing CRRT and IHD from Europe and the USA have been published recently [3-8]. The smallest of these trials was designed to compare the effects of CVVH and IHD on systemic haemodynamics and splanchnic perfusion in patients with septic shock, with an overall mortality of $70 \%$ in both the CVVH and IHD groups [3]. In a US multi-centre trial of 166 patients with AKI, Mehta and colleagues reported intensive care unit and hospital mortality rates of $59.5 \%$ and $65.5 \%$, respectively, in patients randomised to CRRT as compared to $41.5 \%$ and $47.6 \%$, respectively, in patients randomised to IHD $(\mathrm{p}<0.02)$. Again, after covariate adjustment, there was no difference in mortality attributable to modality of RRT [4]. In addition in this study there was a high rate of crossover between the treatment modalities. A US single-centre trial, randomised 80 patients to either CVVHD or IHD, and although greater haemodynamic stability and fluid removal rates were reported with the former, there was no difference in survival [5]. Similarly a Swiss study randomising 125 patients to either CVVHDF or IHD, reported an ICU mortality of $34 \%$ and $38 \%$ respectively for the two modes of RRT, with no difference in final hospital mortality [6]. Once again, the Hemodiafe study, a multicenter randomised controlled trial of 359 patients, also reported no difference in mortality according to mode of RRT used (IHD vs. CVVHDF) [7]. This study is noteworthy as IHD was successfully delivered to patients despite marked haemodynamic instability with very little crossover between treatment groups. The authors deliberately chose cooled dialysate in combination with a very high dialysate sodium concentration to minimise cardiovascular instability during IHD, and compared to other studies delivered the highest $\mathrm{Kt} / \mathrm{V}$ dose in the IHD group. Finally, the SHARF multi-centre collaboration randomised 316 AKI patients to receive either IHD or CVVH and found no impact on outcome [7] although no analysis of the effect or equivalence of delivered dose was provided in this paper.

A number of meta-analyses have been performed. Early work was hampered by inclusion of non-randomised trial data [9] and by limited numbers of randomised trials available at that time [10]. The authors of a more recent meta-analysis were unable to draw any conclusions on modality choice, noting methodological problems in even the most rigorous studies [11]. Another recent metaanalysis reached broadly similar conclusions on modality and although they noted CRRT-treated patients to have higher mean arterial pressures, no significant differences were found in other haemodynamic indices [12].

Noting the absence of outcome difference between modalities, some have turned their attention to cost. Both a retrospective, cohort study [13] and a prospective assessment of cost [14] in a randomised trial [4], have suggested that IHD is cheaper than CRRT. Given the nuances of local resource availability, purchasing practice and clinical practice, this limited data cannot be used as a basis for modality choice at this stage. Studies comparing other forms of RRT have been limited. 
Table 2. Advantages and disadvantages of different RRT modalities in AKI

\begin{tabular}{|c|c|c|c|c|}
\hline Modality & Use in haemodynamically unstable patients & Solute clearance & Volume control & Anti-coagulation \\
\hline Peritoneal dialysis & Yes & Moderate & Moderate & No \\
\hline Intermittent haemodialysis & No & High & Moderate & Possible without \\
\hline $\mathrm{CVVH}$ & Yes & Moderate/high & Good & Possible without \\
\hline CVVHD & Yes & Moderate/high & Good & Possible without \\
\hline CVVHDF & Yes & High & Good & Possible without \\
\hline
\end{tabular}

CVVH: continuous veno-venous haemofiltration; HD: haemodialysis; HDF: haemodiafiltration (see review of nomenclature and physical processes [23])

There are a limited number of studies comparing peritoneal dialysis to CRRT in adults. The former is contraindicated in those with abdominal pathology and may not provide satisfactory clearances in those adults with hypercatabolism or a high urea distribution volume due to fluid overload. Two studies reported an advantage of CRRT, although the dose of dialysis delivered by peritoneal dialysis was low $[15,16]$. In paediatric practice, particularly post cardiac surgery, peritoneal dialysis remains an effective form of RRT, in single organ failure [17]. Most recently, a randomised trial from Brazil has suggested broadly equivalent patient outcomes and metabolic control when PD at high volume (36-44 L/day) was compared to daily IHD prescribed to a spKt/V of 1.2 [18].

Comparative studies of continuous and hybrid techniques are limited. A small trial randomised 39 patients to either CVVH or 12 hour, extended dialysis using a single-pass batch system and found equivalent cardiovascular tolerability and urea clearances but faster correction of acidosis and lower heparin requirements with the latter [19]. Another small, randomised trial compared CVVHDF to a hybrid technique, sustained HDF, which was administered, daily, for 6-8 hours [20]. There was no difference in survival rate at ICU discharge or after 30 days, but the hybrid group had higher renal recovery rates in survivors and a shorter ICU length of stay. The delivered doses in each treatment arm were not clear as diffusive components of continuous and intermittent techniques are kinetically different [21].

In summary, analysis of the currently published studies does not allow evidence-based guidelines for the selection of RRT modality for the treatment of AKI. However, as with the Veterans ATN study, most clinicians chose intermittent haemodialysis/haemofiltration for cardiovascularly stable patients, and continuous or hybrid therapies for those with cardiovascular compromise and multi-organ failure $[22,23]$. The modality chosen should therefore be guided by the individual patient's clinical status, local medical and nursing expertise, and the availability of RRT modality (Table 2 ). 


\section{References}

1 Swartz RD, Messana JM, Orzol S, Port FK. Comparing continuous hemofiltration with hemodialysis in patients with severe acute renal failure. Am J Kidney Dis 1999;34:424-432

$\checkmark 2$ Guerin C, Girard R, Selli JM, Ayzac L. Intermittent versus continuous renal replacement therapy for acute renal failure in intensive care units: Results from a multicenter prospective epidemiological survey. Intensive Care Medicine 2002;28:1411-1418

-3 John S, Griesbach D, Baumgartel M, Weihprecht H, Schmieder RE, Geiger H. Effects of continuous haemofiltration vs. intermittent haemodialysis on systemic haemodynamics and splanchnic regional perfusion in septic shock patients: A prospective, randomized clinical trial. Nephrol Dial Transplant 2001;16:320-327

4 Mehta RL, McDonald B, Gabbai FB, Pahl M, Pascual MT, Farkas A, Kaplan RM, Collaborative Group for Treatment of ARF in ICU. A randomized clinical trial of continuous versus intermittent dialysis for acute renal failure. Kidney Int 2001;60:1154-1163

5 Augustine JJ, Sandy D, Seifert TH, Paganini EP. A randomized controlled trial comparing intermittent with continuous dialysis in patients with ARF. Am J Kidney Dis 2004;44:1000-1007

6 Uehlinger DE, Jakob SM, Ferrari P, Eichelberger M, Huynh-Do U, Marti HP, Mohaupt MG, Vogt B, Rothen HU, Regli B, Takala J, Frey FJ. Comparison of continuous and intermittent renal replacement therapy for acute renal failure. Nephrol Dial Transplant 2005;20:1630-1637. Epub 2005 May 1610

7 Vinsonneau C, Camus C, Combes A, Costa de Beauregard MA, Klouche K, Boulain T, Pallot JL, Chiche JD, Taupin P, Landais P, Dhainaut JF. Continuous venovenous haemodiafiltration versus intermittent haemodialysis for acute renal failure in patients with multiple-organ dysfunction syndrome: A multicentre randomised trial. Lancet 2006; 368:379-385

$>8$ Lins RL, Elseviers MM, Van der Niepen P, Hoste E, Malbrain ML, Damas P, Devriendt J. Intermittent versus continuous renal replacement therapy for acute kidney injury patients admitted to the intensive care unit: Results of a randomized clinical trial. Nephrol Dial Transplant 2009;24:512-518

$\checkmark 9$ Kellum JA, Angus DC, Johnson JP, Leblanc M, Griffin M, Ramakrishnan N, Linde-Zwirble WT. Continuous versus intermittent renal replacement therapy: A meta-analysis. Intensive Care Medicine 2002;28:29-37

10 Tonelli M, Manns B, Feller-Kopman D. Acute renal failure in the intensive care unit: A systematic review of the impact of dialytic modality on mortality and renal recovery.[comment]. Am J Kidney Dis 2002;40: $875-885$

$>11$ Bagshaw SM, Berthiaume LR, Delaney A, Bellomo R. Continuous versus intermittent renal replacement therapy for critically ill patients with acute kidney injury: A meta-analysis. Critical Care Medicine 2008; 36:610-617
12 Rabindranath K, Adams J, Macleod AM, Muirhead N. Intermittent versus continuous renal replacement therapy for acute renal failure in adults. Cochrane Database of Systematic Reviews 2007:CD003773

13 Manns B, Doig CJ, Lee H, Dean S, Tonelli M, Johnson D, Donaldson C. Cost of acute renal failure requiring dialysis in the intensive care unit: Clinical and resource implications of renal recovery. Critical Care Medicine 2003;31:449-455

14 Farese S, Jakob SM, Kalicki R, Frey FJ, Uehlinger DE. Treatment of acute renal failure in the intensive care unit: Lower costs by intermittent dialysis than continuous venovenous hemodiafiltration. Artificial Organs 2009;33:634-640

15 Gangji AS, Rabbat CG, Margetts PJ, Gangji AS, Rabbat CG, Margetts PJ. Benefit of continuous renal replacement therapy in subgroups of acutely ill patients: A retrospective analysis. Clin Nephrol 2005;63:267-275

16 Swartz RD, Bustami RT, Daley JM, Gillespie BW, Port FK, Swartz RD, Bustami RT, Daley JM, Gillespie BW, Port FK. Estimating the impact of renal replacement therapy choice on outcome in severe acute renal failure. Clin Nephrol 2005;63:335-345

17 Strazdins V, Watson AR, Harvey B, European Pediatric Peritoneal Dialysis Working G, Strazdins V, Watson AR, Harvey B, European Pediatric Peritoneal Dialysis Working Group. Renal replacement therapy for acute renal failure in children: European guidelines. Pediatric Nephrology 2004;19:199-207

18 Gabriel DP, Caramori JT, Martim LC, Barretti P, Balbi AL. High volume peritoneal dialysis vs. daily hemodialysis: A randomized, controlled trial in patients with acute kidney injury. Kidney Int 2008;(Suppl):S87-S93

19 Kielstein JT, Kretschmer U, Ernst T, Hafer C, Bahr MJ, Haller H, Fliser D. Efficacy and cardiovascular tolerability of extended dialysis in critically ill patients: A randomized controlled study. Am J Kidney Dis 2004;43: 342-349

20 Abe M, Okada K, Suzuki M, Nagura C, Ishihara Y, Fujii Y, Ikeda K, Kaizu $\mathrm{K}$, Matsumoto K. Comparison of sustained hemodiafiltration with continuous venovenous hemodiafiltration for the treatment of critically ill patients with acute kidney injury. Artificial Organs 2010;34:331-338

-21 Kanagasundaram NS, Paganini EP: Critical care dialysis - a gordian knot (but is untying the right approach?). Nephrol Dial Transplant 1999;14:2590-2594

22 The VA NIH Acute Renal Failure Trial Network, Palevsky PM, Zhang JH, O'Connor TZ, Chertow GM, Crowley ST, Choudhury D, Finkel K, Kellum JA, Paganini E, Schein RM, Smith MW, Swanson KM, Thompson BT, Vijayan A, Watnick S, Star RA, Peduzzi P. Intensity of renal support in critically ill patients with acute kidney injury. N Engl J Med 2008;359:7-20

23 Kanagasundaram NS. Renal replacement therapy in acute kidney injury: An overview. British Journal of Hospital Medicine 2007;68:292-297 


\section{Acute Kidney Injury (AKI) (Guidelines AKI} 7.1-7.3)

\section{Guideline 7.1 - AKI: Choice of dialyser/haemofilter membrane}

We recommend that synthetic or modified cellulosic membranes should be used in preference to unmodified cellulose membranes. (1B)

\section{Guideline 7.2 - AKI: Choice of dialysate/replacement fluid}

We recommend that bicarbonate should be the preferred buffer for dialysate and replacement fluid in continuous renal replacement therapy (CRRT) techniques unless regional citrate anticoagulation is employed. (1C)

Guideline 7.3 - AKI: Microbial standards for fluids

We recommend that microbial standards for fluids used for chronic haemodialysis (HD)/haemodiafiltration (HDF) should be also applied to extracorporeal therapy for AKI. (1A)

\section{Rationale for 7.1-7.3}

Laboratory experiments have shown that synthetic membranes tend to cause less activation of complement and mononuclear cells. Results from clinical trials have, however, been conflicting with some suggesting a survival advantage for more biocompatible membranes [1-4] and others showing no benefit [5-8]. Comparison of individual studies has been compromised by variability in methodology, definitions of AKI, definitions of 'biocompatibility', and in other aspects of dialysis provision, such as timing of initiation and adequacy. No study was blinded.

Meta-analyses have yielded varying results. Subramanian et al. found worse survival with the use of nonbiocompatible membranes although this effect may have been confined to unsubstituted rather than modified cellulose membranes [9]. This meta-analysis did, however, include a large, observational study that may have skewed results in favour of biocompatibility. The most recent Cochrane meta-analysis continues to show no outcome advantage with biocompatible membranes [10]. The definition of non-biocompatibility included both unsubstituted and modified cellulose membranes. Neither meta-analysis could demonstrate a difference in rates of renal recovery. No recommendation can therefore be made about the use of synthetic over modified cellulosic membranes for treating patients with AKI. Adverse survival found with the use of unsubstituted cellulose membranes favours the use of either synthetic or modified cellulose membrane materials. The main determinants of membrane choice will remain technical, with prescription of the dialyser/haemofilter dictated by its intended use.

Lactate and acetate have been largely replaced by bicarbonate as the primary buffer for dialysate used in IHD for established renal failure and this practice has propagated, by default, to IHD for AKI. In a similar fashion, bicarbonate has become the primary buffer for both replacement and dialysate fluids in CRRT. Driven by concerns about exacerbating existing lactic acidosis, particularly in those with liver failure, the development of commercially available bicarbonate-based fluids that circumvent the inherent instability of such solutions has led to their increasing utilisation. Evidence of benefit over lactate-based solutions is inconsistent with some studies showing no substantive differences in metabolic parameters, $\mathrm{pH}$, or haemodynamic status [11] whilst others have shown improved haemodynamic stability $[12,13]$ and more rapid control of systemic acidosis [14]. Despite these conflicting data, the likelihood of benefit, especially in the sickest patients, and the ready availability of commercially-prepared bicarbonate fluid, seems to justify its use in CRRT.

Little comparative data exists on the metabolic effects of citrate- and bicarbonate-based solutions. A singlecentre, prospective sequential cohort study suggested equivalent acid-base and electrolyte control in patients receiving CVVH [15] but numbers were small and substitution fluid infusion rates differed between the two treatment cohorts. Given the absence of high quality evidence no recommendation can be made on the optimal choice for metabolic control between citrateand bicarbonate-based solutions.

A final consideration in the use of dialysate/replacement fluids is their microbial integrity. The potential for clinically significant transfer of pyrogen-inducing material in dialysate and substitution fluids is well recognised in the setting of chronic haemodialysis and haemodiafiltration and has led to the establishment of strict standards for microbiological purity. In the absence of specific evidence for renal support for AKI, it is recommended that these same standards should apply. Intermittent HD will tend to be provided under the auspices of a renal unit so the same water quality standards should already be in place across both acute and chronic services. The need to assure microbial integrity of fluids for CRRTs has not, however, been well recognised although evidence now exists that breaches may well be frequent $[16,17]$. 


\section{References}

1 Himmelfarb J, Tolkoff Rubin N, Chandran P, Parker RA, Wingard RL, Hakim R. A multicenter comparison of dialysis membranes in the treatment of acute renal failure requiring dialysis. J Am Soc Nephrol 1998;9:257-266

2 Hakim RM, Wingard RL, Parker RA. Effect of the dialysis membrane in the treatment of patients with acute renal failure. $\mathrm{N}$ Engl J Med 1994;331:1338-1342

-3 Schiffl H, Lang SM, Konig A, Strasser T, Haider MC, Held E. Biocompatible membranes in acute renal failure: Prospective case-controlled study. Lancet 1994;344:570-572

$\checkmark 4$ Schiffl H, Sitter T, Lang S, Konig A, Haider M, Held E. Bioincompatible membranes place patients with acute renal failure at increased risk of infection. ASAIO Journal 1995;41:M709-M712

5 Albright RC, Jr., Smelser JM, McCarthy JT, Homburger HA, Bergstralh EJ, Larson TS. Patient survival and renal recovery in acute renal failure: Randomized comparison of cellulose acetate and polysulfone membrane dialyzers. Mayo Clinic Proceedings 2000;75:1141-1147

6 Gastaldello K, Melot C, Kahn RJ, Vanherweghem JL, Vincent JL, Tielemans C. Comparison of cellulose diacetate and polysulfone membranes in the outcome of acute renal failure. A prospective randomized study. Nephrol Dial Transplant 2000;15:224-230

7 Jorres A, Gahl GM, Dobis C, Polenakovic MH, Cakalaroski K, Rutkowski B, Kisielnicka E, Krieter DH, Rumpf KW, Guenther C, Gaus W, Hoegel J. Haemodialysis-membrane biocompatibility and mortality of patients with dialysis-dependent acute renal failure: A prospective randomised multicentre trial. International multicentre study group. Lancet 1999;354:1337-1341

$>8$ Kurtal H, von Herrath D, Schaefer K. Is the choice of membrane important for patients with acute renal failure requiring hemodialysis? Artificial Organs 1995;19:391-394
9 Subramanian S, Venkataraman R, Kellum JA. Influence of dialysis membranes on outcomes in acute renal failure: A meta-analysis. Kidney Int 2002;62:1819-1823

10 Alonso A, Lau J, Jaber BL. Biocompatible hemodialysis membranes for acute renal failure. Cochrane Database of Systematic Reviews 2008:CD005283

11 Kierdorf H, Leue C, Heintz B, Riehl J, Melzer H, Sieberth HG. Continuous venovenous hemofiltration in acute renal failure: Is a bicarbonateor lactate-buffered substitution better? Contributions to Nephrology 1995; 116:38-47

12 Thomas AN, Guy JM, Kishen R, Geraghty IF, Bowles BJ, Vadgama P. Comparison of lactate and bicarbonate buffered haemofiltration fluids: Use in critically ill patients. Nephrol Dial Transplant 1997;12:1212-1217

13 Barenbrock M, Hausberg M, Matzkies F, de la Motte S, Schaefer RM. Effects of bicarbonate- and lactate-buffered replacement fluids on cardiovascular outcome in CVVH patients. Kidney Int 2000;58:1751-1757

14 McLean AG, Davenport A, Cox D, Sweny P. Effects of lactate-buffered and lactate-free dialysate in CAVHD patients with and without liver dysfunction. Kidney Int 2000;58:1765-1772

15 Aman J, Nurmohamed SA, Vervloet MG, Groeneveld AB: Metabolic effects of citrate- vs. bicarbonate-based substitution fluid in continuous venovenous hemofiltration: A prospective sequential cohort study. Journal of Critical Care 2010;25:120-127

16 Kanagasundaram NS, Larive AB, Paganini EP. A preliminary survey of bacterial contamination of the dialysate circuit in continuous venovenous hemodialysis. Clin Nephrol 2003;59:47-55

17 Moore I, Bhat R, Hoenich NA, Kilner AJ, Prabhu M, Orr KE, Kanagasundaram NS. A microbiological survey of bicarbonate-based replacement circuits in continuous veno-venous hemofiltration. Critical Care Medicine 2009;37:496-500 


\section{Acute Kidney Injury (AKI) (Guidelines AKI} 8.1-8.6)

\section{Guideline 8.1 - AKI: Vascular access for RRT}

We recommend that acute access for renal replacement therapy should be veno-venous rather than arterio-venous. (1A)

\section{Guideline 8.2 - AKI: Vascular access for RRT}

We recommend that dialysis catheters should be of an adequate length to minimise the risks of access recirculation. (1C)

\section{Guideline 8.3 - AKI: Vascular access for RRT}

We suggest that the access site and catheter type should be chosen with regard to the phase of the patient's illness. (2C)

\section{Guideline 8.4 - AKI: Vascular access for RRT}

We recommend that access should be placed by experienced or appropriately supervised staff. Real-time ultrasound guidance should be used to aid placement of upper body access. (1A)

\section{Guideline 8.5 - AKI: Vascular access for RRT}

We recommend that it is advisable that real-time ultrasound guidance be used for the insertion of femoral access. (1D)

\section{Guideline 8.6 - AKI: Vascular access for RRT}

We recommend that subclavian access should be avoided in patients at risk of progressing to CKD stage 4 or 5 due to the risks of compromising future, permanent vascular access. (1D)

\section{Guideline 8.7 - AKI: Vascular access for RRT}

We suggest that non-dominant arm upper limb vasculature should be preserved as a contingency for future permanent access. (2C)

\section{Guideline 8.8 - AKI: Vascular access for RRT}

We recommend that temporary access should be changed at appropriate intervals (as per local protocol) to minimise the risk of infection. (1C)

\section{Guideline 8.9 - AKI: Vascular access for RRT}

We suggest that local policies on prevention of catheter-related infection should be optimised by reserving the catheter for extracorporeal treatment only. (1D)

\section{Audit measure}

1. Incidence of dialysis catheter-related bacteraemia and sepsis in patients with AKI

\section{Rationale for 8.1-8.9}

In industrialised societies, the vast majority of continuous therapy is now provided using pumped, veno-venous methods [1]. Not only does this technique support the requirement for adequate blood flow rates to achieve the higher ultrafiltration/dialysate flow rates used in modern CRRT, but it also avoids the potential hazards of the acute arterio-venous access used historically [2]. The adequacy of intermittent techniques is much more dependent on delivered, extracorporeal blood flow. Catheter failure is a frequent cause of under-delivery of the prescribed IHD dose [3] and should be borne in mind as a cause of any prescription-delivery shortfall. Temporary vascular access used in acute dialysis may lead to levels of access recirculation of nearly $40 \%$ depending on the site and length of access, blood flow and reversal of the lines [4].

Several venous catheters are available, with the duallumen design being the most popular because of ease of insertion and good flow characteristics [5]. Such catheters usually have a double-D cross-sectional profile and are amenable to guide wire changes [6]. Catheters made of semi-rigid polyurethane or softer silicone are regarded as the best in terms of thrombogenicity [1]. The former are a reasonable short-term option $(<3$ weeks) while the latter might be best utilised for longer term dialysis because of the lower propensity to cause endovascular trauma [1]. Such catheters, used with subcutaneous tunnelling, are highly desirable if RRT is likely to be prolonged ( $>3$ weeks) [7]. A small, single-centre, randomised control trial compared the performance of tunnelled to non-tunnelled femoral catheters inserted in AKI patients prior to initiation of renal support [8]. Tunnelled access was found to give better flow characteristics, fewer post-insertion complications, greater longevity and less likelihood of a prescription-delivery shortfall. There were, however, more insertion failures in this group and successful catheter placements took significantly longer. Of note, all catheters insertions were performed by a single operator. The applicability of these findings to routine practice is unclear.

Use of real-time ultrasound guidance for catheter placement at upper body sites has been demonstrated to be associated with greater success and fewer complications [9]. It is advisable that similar guidance be used for femoral catheter insertion. 
A number of factors should be taken into consideration in choosing a site for insertion and appropriate catheter length. Femoral catheters shorter than $20 \mathrm{~cm}$ from hub to tip are associated with higher degrees of access recirculation $[4,10]$. Femoral catheters of at least $24 \mathrm{~cm}$ in length may produce improved flow rates [6]. Because of the risks of infection and femoral vein thrombosis, it is recommended that femoral catheters be removed and replaced on at least a weekly basis $[6,11]$. It is advisable that femoral catheters be replaced by upper body access once the patient starts to mobilise.

The subclavian approach carries with it the long-term risk of venous stenosis that may compromise future, ipsilateral, permanent upper limb arteriovenous access. Subclavian access is thus best avoided in those with a likelihood of progressing to CKD stage 4 or 5 . The internal jugular approach may be associated with a lower incidence of both accidental pneumothorax [6] and long-term venous stenosis [12] in comparison with subclavian access, and is the preferred upper body access. Infection may be somewhat more common than at the subclavian site, however, especially in patients with tracheostomies [12].

For the average adult, internal jugular vein catheters should be around $20 \mathrm{~cm}$ in length on the right and $24 \mathrm{~cm}$ on the left [12], to ensure safe positioning of the catheter tip in the lower superior vena cava. With appropriate infection control and catheter care, upper body access may only need replacement every 2-3 weeks $[12,13]$. Local guidelines may suggest a more frequent schedule of replacement and should be adhered to.
Catheter-related bacteraemia and exit site infection are significant risks of temporary access for acute RRT [14]. Fastidious insertion technique by experienced or appropriately supervised staff and rigorous catheter care can reduce this risk [15]. It is advisable that dialysis catheters be reserved solely for the purpose of RRT as repeated manipulations for non-RRT related reasons may increase the risk of contamination. Guidewireexchange of catheters for non-infection related reasons may not increase bacteraemia rates [11] but cannot be recommended in the presence of catheter-related bacteraemia or exit-site infection. Between periods of RRT catheters may be locked with heparin 1000 units $/ \mathrm{ml}$ to lumen volumes unless there is a clear contraindication. It is recommended that higher concentrations be avoided due to the risks associated with over-dosing and leakage of the lock into the systemic circulation. Alternatives to heparin to reduce infection risks include heparin and antibiotic combinations, citralock and taurolock although no high quality data currently exists that would support their routine use. Recently, antimicrobial catheters have been introduced for vascular access, either impregnated with silver or antibiotic coated. Preliminary trials have suggested a reduction in the incidence of catheter associated bacteraemia but larger trials will be required before the use of these catheters can be recommended as standard practice.

In patients who are likely to progress to stage 4 or 5 $\mathrm{CKD}$, upper limb vasculature should be preserved as a contingency for future permanent vascular access [7]. 


\section{References}

$>1$ Canaud B, Leray-Moragues H, Leblanc M, Klouche K, Vela C, Beraud JJ. Temporary vascular access for extracorporeal renal replacement therapies in acute renal failure patients. Kidney Int 1998;53:S142-S150

-2 Storck M, Hartl WH, Zimmerer E, Inthorn D. Comparison of pumpdriven and spontaneous continuous haemofiltration in postoperative acute renal failure. Lancet 1991;337:452-455

3 Kanagasundaram NS, Greene T, Larive AB, Daugirdas JT, Depner TA, Garcia M, Paganini EP. Prescribing an equilibrated intermittent hemodialysis dose in intensive care unit acute renal failure. Kidney Int 2003;64:2298-2310

4 Kelber J, Delmez JA, Windus DW. Factors affecting delivery of highefficiency dialysis using temporary vascular access. Am J Kidney Dis 1993;22:24-29

$\checkmark 5$ Tapson JS, Hoenich NA, Wilkinson R, Ward MK. Dual lumen subclavian catheters for haemodialysis. International Journal of Artificial Organs 1985;8:195-200

$\checkmark 6$ Uldall R. Vascular access for continuous renal replacement therapy. Seminars in Dialysis 1996;9:93-97

7 Canaud B, Desmeules S, Klouche K, Leray-Moragues H, Beraud JJ. Vascular access for dialysis in the intensive care unit. Best Practice \& Research Clinical Anaesthesiology 2004;18:159-174

8 Klouche K, Amigues L, Deleuze S, Beraud JJ, Canaud B. Complications, effects on dialysis dose, and survival of tunneled femoral dialysis catheters in acute renal failure. Am J Kidney Dis 2007;49:99-108
9 Anonymous: NICE technology appraisal guidance, no. 49 - guidance on the use of ultrasound locating devices for placing central venous catheters, National Institute for Clinical Excellence, 2002

10 Leblanc M, Fedak S, Mokris G, Paganini EP. Blood recirculation in temporary central catheters for acute hemodialysis. Clin Nephrol 1996;45:315-319

11 Oliver MJ, Callery SM, Thorpe KE, Schwab SJ, Churchill DN. Risk of bacteremia from temporary hemodialysis catheters by site of insertion and duration of use: A prospective study. Kidney Int 2000;58:2543-2545

12 Cimochowski GE, Worley E, Rutherford WE, Sartain J, Blondin J, Harter H. Superiority of the internal jugular over the subclavian access for temporary dialysis. Nephron 1990;54:154-161

13 Weijmer MC, Vervloet MG, ter Wee PM. Compared to tunnelled cuffed haemodialysis catheters, temporary untunnelled catheters are associated with more complications already within 2 weeks of use. Nephrol Dial Transplant 2004;19:670-677

14 Kairaitis LK, Gottlieb T. Outcome and complications of temporary haemodialysis catheters. Nephrol Dial Transplant 1999;14:1710-1714

15 Deshpande KS, Hatem C, Ulrich HL, Currie BP, Aldrich TK, BryanBrown CW, Kvetan V. The incidence of infectious complications of central venous catheters at the subclavian, internal jugular, and femoral sites in an intensive care unit population. Crit Care Med 2005;33:13-20; discussion 234-235 


\section{Acute Kidney Injury (AKI) (Guidelines AKI} 9.1-9.4)

\section{Guideline 9.1 - AKI: Anticoagulation for extracorporeal therapies}

We recommend that anticoagulation for RRT should be tailored according to patient characteristics and the modality of RRT chosen. (1C)

\section{Guideline 9.2 - AKI: Anticoagulation for extracorporeal therapies}

We recommend that regional anticoagulation with citrate reduces risk of haemorrhage compared to systemic heparinisation. The complexity of the technique means that this should be in routine use on any unit on which it is employed in order to allow sufficient levels of expertise to be maintained. (1C)

\section{Guideline 9.3 - AKI: Anticoagulation for extracorporeal therapies}

We suggest that prostacyclin is a suitable alternative to unfractionated heparin in those at increased risk of bleeding, but may cause haemodynamic instability. (2C)

\section{Guideline 9.4 - AKI: Anticoagulation for extracorporeal therapies}

We suggest that a no-anticoagulation, saline flush strategy can be used in patients receiving continuous and intermittent RRT who are at high risk of bleeding. However, ultrafiltration requirements are increased, effective intermittent HD time is reduced and the technique runs the risk of membrane fibre rupture. (2C)

\section{Audit measure}

1. Incidence of heparin induced thrombocytopenia

\section{Rationale for 9.1-9.4}

Clotting of the extracorporeal circuit is a significant source of under-delivery of the prescribed dose of RRT and is the most frequent cause of therapy interruption in CRRT. The hypercoaguable state of the critically-ill patient with AKI [1] compounds various technical factors such as non-laminar flow within both the vascular access and circuit, blood-membrane interactions, the air-blood interface in the venous bubble trap and the haemoconcentration induced by high ultrafiltration volumes used in CVVH/CVVHDF.

The most widely used anticoagulant for RRT in patients with AKI is unfractionated heparin (UFH) [2, 3]. Although an effective anticoagulant for IHD in patients with CKD, UFH may be less effective in AKI, as many critically ill patients have reduced levels of antithrombin, especially when used for patients treated with CRRT. In addition, systemic heparinisation is associated with a risk of bleeding and also with the development of heparin-induced thrombocytopenia (HIT) [4, 5]. Low molecular weight heparins have generally not been shown to be superior over UFH and have an extended half life in AKI and require monitoring with anti-Xa activity [3].

Regional heparin protocols, with reversal of heparin by infusion of protamine into the return line, have been developed to prevent systemic anticoagulation and minimise bleeding risk. Unfortunately, these protocols are cumbersome, may be associated with paradoxical increased risk of bleeding if excess protamine is infused, and do not alter the risk of HIT. Other anticoagulants that can be used as alternatives for anticoagulation of the extracorporeal circuit in patients with a history of HIT include prostacyclin (prostaglandin $\mathrm{I}_{2}$ - which is used in non-HIT patients who are at high risk of bleeding) [6-9], hirudin, nafamostat, and argatroban [3]. The synthetic heparinoids, danaparoid and fondiparinux may also be used, although cross reactivity with the HIT antibodies has occasionally been reported. If these agents are used and the peripheral platelet count does not increase within 72 hours cross reactivity should be excluded Argatroban is currently not licensed in the $\mathrm{UK}$, and has to be given by continuous infusion. Danaparoid, fondiparinux and hirudin are all renally excreted and therefore have extended half lives in AKI.

The synthetic heparinoids require monitoring of anti-Xa activity and hirudin by either its plasma concentration or the ecarin clotting time. Hirudin is partially cleared by high flux membranes, but the majority of patients given hirudin for CRRT develop antibodies to hirudin, which reduce its clearance and extend its half life so increasing the risk of haemorrhage. In cases of excess anticoagulation associated with bleeding, there are no specific antidotes for these agents, unlike protamine for unfractionated heparin. Although activated factor VII has been shown to be effective and hirudin can be cleared by high flux dialysis/CRRT plasma exchange is required in cases of hirudin antibodies [3].

Over the last decade citrate has emerged as a very effective regional anticoagulant for use in CRRT [1014]. Citrate is infused into the pre-filter line and works by chelating calcium. Calcium is then re-infused separately, or into the return line, to maintain normal 
systemic ionised calcium concentrations. Commercially available citrate systems have not been available until recently, so individual units developed their own protocols for citrate anticoagulation. Citrate comes as a sodium salt, and each molecule is indirectly converted to three bicarbonates, so there can potentially be changes in sodium balance and acid-base status depending upon the citrate load and the ability of the patient to adequately metabolise citrate.

There have been few prospective comparative studies of UFH and citrate anticoagulation. In two CRRT studies the median circuit survival time was significantly prolonged with citrate ( $70 \mathrm{hr} \mathrm{v} .40 \mathrm{hr}$ and $124 \mathrm{v} .38 \mathrm{hr}$ ) and there was reduced blood transfusion requirements and/ or haemorrhage in the citrate groups $[10,11]$. However patients that cannot adequately metabolise citrate to bicarbonate, such as those with acute liver failure, may develop a 'calcium gap' due to the accumulation of calcium citrate complex. The 'calcium gap' is the calcium complexed with citrate, and is the difference between the total calcium measured and that due to ionised calcium and plasma protein bound calcium. As these patients cannot adequately metabolise citrate, they will develop a metabolic acidosis with hypercitrataemia. On the other hand, over administration of citrate to patients who can metabolise the citrate load will result in a systemic alkalosis. In Japan, nafamostat is used as a regional anticoagulant, and appears to have similar efficacy and safety profile to citrate.

Although UFH remains the most commonly employed extracorporeal anticoagulant for RRT in patients with AKI, there is emerging data to support the safety and potential superiority of regional citrate anticoagulation for CRRT. Now that citrate based anticoagulation systems have been developed for CRRT by the major commercial companies, the proportion of patients with AKI treated by citrate systems may increase.

The short duration of intermittent techniques may allow a 'minimal' heparin (e.g. $500 \mathrm{IU} /$ hour) or even no heparin strategy. Regular saline flushes, used to sustain the latter, may, however, reduce the effective dialysis time. No heparin use in CRRT is possible and can achieve adequate solute clearances but its disadvantages include the need for increased ultrafiltration, the potential risk of dialyser fibre rupture and additional nursing workload $[15,16]$.

Finally, pre-dilutional fluid replacement during continuous haemofiltration can help minimise the haemoconcentration induced by large ultrafiltration volumes but comes at the price of the inefficiency of ultrafiltering a mixture of just-infused replacement fluid and plasma the proportions of which are important considerations in the CRRT prescription. 


\section{References}

1 Davenport A. The coagulation system in the critically ill patient with acute renal failure and the effect of an extracorporeal circuit. Am J Kidney Dis 1997;30:S20-S27

2 Davenport A, Mehta S. The Acute Dialysis Quality Initiative - part VI: access and anticoagulation in CRRT. Adv Ren Replace Ther. 2002; 9:273-281

3 Oudemans-van-Straaten HM, Wester JPJ, Pont ACJM de, Schetz MRC. Anticoagulation strategies in continuous renal replacement therapy: can the choice be evidence based? Intensive Care Med 2006; 32:188-202

$\checkmark 4$ Mehta RL. Anticoagulation strategies for continuous renal replacement therapies: what works? Am J Kidney Dis 28:S8-S14, 1996

5 Davenport A. Management of heparin-induced thrombocytopenia during continuous renal replacement therapy. Am J Kidney Dis 1998; 32:E3

6 Ponikvar R, Kandus A, Buturovic J, Kveder R. Use of prostacyclin as the only anticoagulant during continuous venovenous hemofiltration. Contributions to Nephrology 1991;93:218-220

7 Journois D, Chanu D, Pouard P, Mauriat P, Safran D. Assessment of standardized ultrafiltrate production rate using prostacyclin in continuous venovenous hemofiltration. Contributions to Nephrology 1991; 93:202-204

8 Davenport A, Will EJ, Davison AM. Comparison of the use of standard heparin and prostacyclin anticoagulation in spontaneous and pumpdriven extracorporeal circuits in patients with combined acute renal and hepatic failure. Nephron 1994;66:431-437
9 Langenecker SA, Felfernig M, Werba A, Mueller CM, Chiari A, Zimpfer M. Anticoagulation with prostacyclin and heparin during continuous venovenous hemofiltration. Crit Care Med 1994;22:1774-1781

10 Monchi M, Berghmans D, Ledoux D et al. Citrate vs. heparin for anticoagulation in continuous venovenous hemofiltration: a prospective randomized study. Intensive Care Med. 2004;30:260-265

11 Kutsogiannis DJ, Gibney RT, Stollery D, Gao J. Regional citrate versus systemic heparin anticoagulation for continuous renal replacement in critically ill patients. Kidney Int. 2005;67:2361-2367

12 Palsson R, Niles JL. Regional citrate anticoagulation in continuous venovenous hemofiltration in critically ill patients with a high risk of bleeding. Kidney Int 1999;55:1991-1997

13 Mehta RL, McDonald BR, Aguilar MM, Ward DM. Regional citrate anticoagulation for continuous arteriovenous hemodialysis in critically ill patients. Kidney Int 1990;38:976-981

14 Kirschbaum B, Galishoff M, Reines HD: Lactic acidosis treated with continuous hemodiafiltration and regional citrate anticoagulation. Crit Care Med 1992;20:349-353

15 Smith D, Paganini EP, Suhoza K, Eisele G, Swann S, Nakamoto S. Nonheparin continuous renal replacement therapy is possible, in Progress in Artificial Organs - 1985, edited by Nose Y, Kjellstrand C, Ivanovich P, Cleveland, ISAO Press, 1986, pp 226-230

16 Ramesh Prasad GV, Palevsky PM, Burr R, Lesko JM, Gupta B, Greenberg A. Factors affecting system clotting in continuous renal replacement therapy: results of a randomized, controlled trial. Clin Nephrol 53:55-60;2000 


\section{Acute Kidney Injury (AKI) (Guidelines AKI 10.1-10.5)}

\section{Guideline 10.1 - AKI: Renal Replacement Therapy prescription}

We recommend that the delivered dose of RRT should be assessed to ensure the adequacy of the prescription. (1A)

\section{Guideline 10.2 - AKI: Renal Replacement Therapy prescription}

We recommend that the prescribed dose should be assessed at each session (for intermittent haemodialysis) and daily (for continuous RRT) to account for any measured shortfalls in delivered dose. (1A)

\section{Guideline 10.3 - AKI: Renal Replacement Therapy prescription}

We recommend that patients with AKI and multiorgan failure treated by continuous renal replacement therapy (CRRT) should receive treatment doses equivalent to post dilution ultrafiltration rates $\geqslant 25 \mathrm{ml} / \mathrm{kg} / \mathrm{hr}$. A proportionate upward adjustment to the prescribed ultrafiltration rate should be made in pre-dilutional continuous haemofiltration. (1A)

\section{Guideline 10.4 - AKI: Renal Replacement Therapy prescription}

We recommend that patients with AKI and multiorgan failure treated by intermittent haemodialysis should receive either alternate day haemodialysis with at least the minimum dose considered appropriate for end-stage renal disease (ESRD), urea reduction ratio (URR) $>65 \%$ or $\mathrm{eKt} / \mathrm{V}>1.2$ or daily haemodialysis. (1B)

\section{Guideline 10.5 - AKI: Renal Replacement Therapy prescription}

We suggest that renal replacement therapy dosing methods that require an assessment of patient weight should use a measured weight rather than an extrapolated weight from pre-morbid readings. (2B)

\section{Audit measures}

1. Proportion of critically ill patients treated by alternate day haemodialysis who receive $\mathrm{eKt} / \mathrm{V}$ $\geqslant 1.2$ per session

2. Proportion of critically ill patients with AKI treated with continuous renal replacement therapy who receive $>25 \mathrm{mls} / \mathrm{kg} / \mathrm{hr}$ post-dilution ultrafiltration

\section{Rationale for 10.1-10.5}

Traditionally in studies in patients with AKI, the dose (or intensity) of treatment has been assessed by urea clearance in dialysis based modalities, and by ultrafiltration volume (a surrogate of urea clearance), in the convective therapies. Urea is relatively non-toxic and regarded as a surrogate for other low molecular weight uraemic toxins. It is recognised that using urea as a marker of intensity or dose of RRT has a number of limitations particularly in critically ill patients. Urea generation rates will differ between patients, due to patient specific factors (age, sex and race etc), due to disease specific factors (the catabolic rate, the presence of muscle injury and/or breakdown, sepsis and liver disease) and due to medical therapy such as nutritional support and steroid treatment. However given the current absence of any other more suitable marker urea clearance is accepted as the best way to compare intensity or dose of RRT. The urea clearance achieved during CRRT is approximately equal to the effluent flow rate (dialysis and ultrafiltration flow rate combined).

The dose of RRT delivered to patients not only includes small solute clearances but also larger 'middle' molecules. The amount of these other molecules removed will depend on the modality used and is greater for convective (haemofiltration) than diffusion (dialysis) based techniques. Middle molecule clearance by intermittent therapies is also affected by both frequency and duration of therapy. In addition to solute clearances, the prescription and delivery of renal support to patients with AKI also includes other key aspects of medical management, including sodium and water balance (patients are often grossly salt-and volume-loaded by the time they reach the need for RRT; drug carriage solutions and colloids will compound this, even when the period of 'active' renal re-perfusion has ceased), and correction of acid-base imbalance. There are fundamental differences in provision of RRT to patients with established renal failure compared to those with AKI including the wide, intra- and inter-individual variability in key clinical and dialytic factors, such as total body water and the catabolic rate [1]. Thus, the prescription of a dose of RRT and assessment of its delivery will need to be undertaken daily (for CRRT) and at each session (for IRRT).

There is a paucity of data regarding 'adequate' treatment doses of intermittent haemodialysis (IHD) to be delivered in AKI. Analysis of a prospectively collected database has shown that higher doses of intermittent haemodialysis, defined as a urea reduction ratio (URR) 
$>58 \%$, improved survival [2]. It should be noted that this cut-off dose, equivalent to a $\mathrm{Kt} / \mathrm{V}$ of around 1 , is lower than that recommended for IHD for established renal failure. In this study dialysis dose had no impact on patient survival in patients at the extremes of illness severity. Whereas, for those patients with intermediate severity of illness, the delivery of dialysis dose in excess of the 50th percentile $(\mathrm{Kt} / \mathrm{V} \sim 1)$ was associated with lower mortality risk than lower doses [3].

Due to the lack of prospective studies addressing the minimum dose of RRT required in AKI a consensus panel convened by the multinational Acute Dialysis Quality Initiative (ADQI) recommended that patients with AKI receive at least the minimum dose that is considered appropriate for patients with established renal failure [4]. Recently the Veterans trial reported that there was no significant improvement in patient outcomes provided a $\mathrm{Kt} / \mathrm{V}$ of $1.2-1.4$ per session was delivered [5]. Due to the difficulty in assessing the volume of distribution of urea in patients with AKI, several studies have shown that the delivered dose of IHD can be markedly lower than that prescribed $[2,6]$, and is not routinely measured in clinical practice. However it must be stressed that weight-based RRT dosing is important and should be performed. To achieve a URR above $65 \%$ or eKt/V above 1.2 consistently in the vast majority of the haemodialysis population clinicians should aim for a minimum target URR of $70 \%$ or minimum eKt/V of 1.4 in individual patients.

Only one study has evaluated the effect of daily and alternate day IHD on the outcome among patients with AKI [7]. This reported both lower mortality (28\% v. $46 \%, \mathrm{p}=0.01)$ and shorter duration of AKI $(9 \pm 2 \mathrm{v}$. $16 \pm 6$ days, $p=0.001$ ) in the daily IHD group. However the dose of haemodialysis delivered to the alternate day group was low (mean delivered $\mathrm{Kt} / \mathrm{V}$ of $0.94 \pm 0.11$ ). This probably accounted for the markedly increased time-averaged urea concentration, and the high incidence of complications including gastrointestinal bleeding, mental status alteration, and infection reported in this group.

Several studies have looked at dose in CRRT $[5,8-11]$. In a large single centre randomised controlled trial the 435 enrolled patients were randomised to one of three continuous venovenous haemofiltration $(\mathrm{CVVH})$ doses (post dilution). The doses were defined by achieved daily ultrafiltration rates of $20 \mathrm{ml} / \mathrm{kg} / \mathrm{hr}, 35 \mathrm{ml} / \mathrm{kg} / \mathrm{hr}$, and $45 \mathrm{ml} / \mathrm{kg} / \mathrm{hr}$ [8]. Mortality was markedly lower in the intermediate and high dose arms $(43 \%$ and $42 \%$, respectively) compared to the low dose arm (59\%, $\mathrm{p}<0.001)$. Subsequently there have been three further studies comparing the dose of CRRT. Two smaller studies failed to show any survival benefit $[10,11]$. However survival benefit was demonstrated in a study that added an additional dose of dialysis to haemofiltration providing an equivalent dose of $35 \mathrm{ml} / \mathrm{kg} / \mathrm{hr}$ [11].

An important technical consideration is that the slow dialysate flow rates employed in continuous venovenous haemodialysis (CVVHD) and haemodiafiltration (HDF) ensures that the effluent fluid will be fully equilibrated with plasma with respect to small solutes by the time it leaves the dialyser [12]. Ultrafiltration rates in convective treatments (haemofiltration) can thus be used, interchangeably, with dialysate flow rates for the CRRTs when considering urea clearances [13].

Two large multicentre randomised controlled studies have been published recently to provide much needed guidance on the optimal dose of CRRT in critically ill patients. The Veteran Affairs/National Institute of Health Acute Renal Failure Trial Network (ATN) study was performed in ICUs across the USA [5] whilst the Randomised Evaluation of Normal Versus Augmented Level Renal Replacement Therapy (RENAL) was conducted in ICUs in Australia and New Zealand [14]. The ATN study showed no additional beneficial patient outcome with a delivered CVVHDF dose (pre-dilution) of $35 \mathrm{ml} / \mathrm{kg} / \mathrm{h}$ compared to $20 \mathrm{ml} / \mathrm{kg} / \mathrm{h}$, although there was a non significant trend for better outcome in the more critically ill patients with the higher dose of RRT [5]. The RENAL trial failed to demonstrate any survival benefit from receiving post dilution CVVHDF at a dose of $40 \mathrm{ml} / \mathrm{kg} / \mathrm{hr}$ versus $25 \mathrm{ml} / \mathrm{kg} / \mathrm{hr}$. These studies have now provided evidence that there is no survival benefit in critically ill patients receiving ultrafiltration doses $>25 \mathrm{ml} / \mathrm{kg} / \mathrm{hr}$. This suggests that a minimum delivered dose of $25 \mathrm{ml} / \mathrm{kg} / \mathrm{h}$ is required, and to allow for circuit clotting, a higher dose should be prescribed, particularly for the critically ill patient.

There is little data on dose comparisons in critically ill patients receiving peritoneal dialysis (PD). A more recent study CRRT was reported to be superior to PD in treating patients with malaria induced AKI [15], and this may have well have been due to the dose of PD delivered, as the rate of creatinine clearance and correction of acidosis were much inferior during PD therapy. Peritoneal dialysis has been shown to be an effective therapy in children post cardiac surgery [16], when a PD dose in excess of a weekly $\mathrm{Kt} / \mathrm{V}$ urea of 2.1 was delivered, with a median creatinine clearance of $74.3 \mathrm{~L} / \mathrm{wk} / 1.73 \mathrm{~m}^{2}$. Automated peritoneal dialysis machines are the preferred 
method for delivering individualised peritoneal dialysis dose and accurately measuring ultrafiltration.

Just as there are no studies looking at the dose of peritoneal dialysis required for patients with single organ and multiple organ failure, there is a similar paucity of data on patient outcomes with the recently introduced 'hybrid' treatments (such as Genius ${ }^{\circledR}$, extended daily dialysis (EDD), and sustained lowefficiency dialysis (SLED)). Only a relatively small number of patients were treated by hybrid therapies in the Veterans study, but there was no obvious improvement in patient outcomes with more intensive therapy above alternate day sessions delivering a $\mathrm{Kt} / \mathrm{V}$ of $\geqslant 1.3$ [5]. However it must be remembered that if intermittent haemodialysis, EDD and/or SLED techniques are used in the intensive care unit, unless there is a dedicated water treatment plant available, the simple treatment of domestic water with a single reverse osmosis unit and ultrafilters may not provide the quality of water required for haemodiafiltration, unless batch dialysate systems $\left(\right.$ Genius ${ }^{\circledR}$ ) are used. The ATN study did not show any major benefit for either intensive haemodialysis, hybrid therapies or CVVHDF [5], but the amount of intermittent haemodialysis and/or hybrid therapy delivered per session was greater than in earlier studies.

\section{References}

1 Kanagasundaram NS, Paganini P. Acute renal failure on the intensive care unit. Clin Med 2005;5:435-440

-2 Kanagasundaram NS, Greene T, Larive AB, Daugirdas JT, Depner TA, Garcia M, Paganini EP. Prescribing an equilibrated intermittent hemodialysis dose in intensive care unit acute renal failure. Kidney Int 2003;64:2298-2310

3 Paganini EP, Tapolyai M, Goormastic M, Halstenberg W, Kozlowski L, Leblanc M, Lee JC, Moreno L, Sakai K. Establishing a dialysis therapy/patient outcome link in intensive care unit acute dialysis for patients with acute renal failure. Am J Kidney Dis 1996;28:S81-S89

$\checkmark 4$ Kellum JA, Mehta RL, Angus DC, Palevsky P, Ronco C. The first international consensus conference on continuous renal replacement therapy. Kidney Int. 2002;62:1855-1863

$\checkmark 5$ The VA/NIH acute renal failure trial network. Intensity of renal support in critically ill patients with acute kidney injury. N Engl J Med 2008;359

-6 Evanson JA, Himmelfarb J, Wingard R et al. Prescribed versus delivered dialysis in acute renal failure patients. Am J Kidney Dis. 1998;32: $731-738$

$\checkmark 7$ Schiffl H, Lang SM, Fischer R. Daily hemodialysis and the outcome of acute renal failure. N Engl J Med. 2002;346:305-310

$>8$ Ronco C, Bellomo R, Homel P et al. Effects of different doses in continuous veno-venous haemofiltration on outcomes of acute renal failure: a prospective randomised trial. Lancet. 2000;356:26-30

-9 Bouman CS, Oudemans-Van Straaten HM, Tijssen JG et al. Effects of early high-volume continuous venovenous hemofiltration on survival and recovery of renal function in intensive care patients with acute renal failure: a prospective, randomized trial. Crit Care Med. 2002;30:2205-2211

10 Tolwani AJ, Campbell RC, Stofan BS et al. Standard versus high dose CVVHDF for intensive care unit related acute renal failure. J Am Soc Nephrol 2008 Epub PMID 18337480

11 Saudan P, Niederberger M, De Seigneux S, Romand J, Pugin J, Perneger T, Martin PY. Adding a dialysis dose to continuous haemofiltration increases survival in patients with acute renal failure. Kidney Int 2006;70:1312-1317

12 Bellomo R. Do we know the optimal dose for renal replacement therapy in the intensive care unit? Kidney Int 2006;70:1202-1204

13 Sigler MH. Transport characteristics of the slow therapies: implications for achieving adequacy of dialysis in acute renal failure. Advances in Renal Replacement Therapy 1997;4:68-80

14 RENAL Replacement Therapy Study Investigators. Intensity of continuous renal replacement therapy in critically ill patients. $\mathrm{N}$ Engl J Med. 2009;361:1627-1638

15 Phu NH, Hien TT, Mai NT et al. Hemofiltration and peritoneal dialysis in infection-associated acute renal failure in Vietnam. N Engl J Med. 2002;347:895-902

16 McNeice KL, Ellis EE, Drummond-Webb JJ, Fontenot EE, O'Grady CM, Blaszak RT. Adequacy of peritoneal dialysis in patients following cardiopulmonary bypass surgery. Pediatr Nephrol 2005;20:972-976 


\section{Acute Kidney Injury (AKI) (Guidelines AKI 11.1-11.5)}

\section{Guideline 11.1 - AKI: Timing of initiation of renal replacement treatment}

We recommend that the decision to start RRT in patients with AKI should remain a clinical decision based on fluid, electrolyte and metabolic status of each individual patient. (1C)

Guideline 11.2 - AKI: Timing of initiation of renal replacement treatment

We recommend that RRT should be initiated once AKI is established and unavoidable but before overt complications have developed. (1B)

\section{Guideline 11.3 - AKI: Timing of initiation of renal replacement treatment}

We recommend that the threshold for initiating RRT should be lowered when AKI occurs as part of multiorgan failure. (1C)

\section{Guideline 11.4 - AKI: Timing of initiation of renal replacement treatment}

We recommend that the initiation of RRT may be deferred if the underlying clinical condition is improving and there are early signs of renal recovery. (1D)

\section{Guideline 11.5 - AKI: Timing of discontinuation of renal replacement treatment}

We recommend that an improvement in the patient's clinical condition and urine output would justify temporary discontinuation of ongoing renal support to see if AKI is recovering. (1D)

\section{Rationale for 11.1-11.5}

Historic data suggests that 'early' initiation of RRT in AKI is associated with improved survival but the evidence base is not sufficiently robust to allow a specific recommendation and the decision to initiate RRT should remain a clinical decision (Table 3 ). Whereas the decision to initiate RRT is straightforward in those patients with refractory hyperkalaemia, metabolic acidosis and volume overload, and/or overt uraemic symptoms, in the absence of these overt manifestations there is debate as to the optimal time to initiate renal support. Early introduction of RRT as soon as a patient enters AKI stage 3, may be of benefit, so that the patient is not exposed to the potential deleterious effects of metabolic abnormalities and/or volume overload. However, early initiation of RRT will result in some patients suffering the adverse consequences of treatment, such as venous thrombosis and catheter-related bacteraemia, haemorrhage from anticoagulants, and other treatment related complications. In addition some patients with AKI, especially those with single organ failure, may recover renal function without ever developing an 'absolute' indication for RRT. Finally, animal work has suggested that RRT might delay renal recovery [1] although it is not clear whether more modern techniques of renal support also might be implicated.

Initial reports, some dating back 50 years, suggested a clinical benefit of early initiation of RRT. These and other studies [2-8] formed the basis for the standard clinical practice that dialytic support should be instituted when the serum urea reached $28 \mathrm{mmol} / \mathrm{l}$. In recent years, several retrospective studies have reported improved clinical outcomes with early institution of CRRT for post-traumatic AKI at urea levels $<21.5 \mathrm{mmol} / 1$ [9], or

Table 3. Indications generally used to start renal replacement therapy in standard clinical practice in patients with AKI

\begin{tabular}{ll}
\hline Biochemical indications & Clinical indications \\
\hline $\begin{array}{l}\text { Refractory hyperkalaemia }>6.5 \mathrm{mmol} / \mathrm{l} \\
\text { Serum urea }>27 \mathrm{mmol} / \mathrm{l}\end{array}$ & $\begin{array}{l}\text { Urine output }<0.3 \mathrm{ml} / \mathrm{kg} \text { for } 24 \text { hrs or absolute anuria for } 12 \text { hrs } \\
\text { AKI with multiple organ failure }\end{array}$ \\
$\begin{array}{l}\text { Refractory metabolic acidosis } \mathrm{pH}<7.15 \\
\text { Refractory electrolyte abnormalities: }\end{array}$ & $\begin{array}{l}\text { Refractory volume overload } \\
\text { End organ involvement: pericarditis, encephalopathy, } \\
\text { Hyponatraemia, hypernatraemia or hypercalcaemia }\end{array}$ \\
$\begin{array}{l}\text { Tumour lysis syndrome with hyperuricaemia and } \\
\text { hyperphosphataemia }\end{array}$ & $\begin{array}{c}\text { Creation of intravascular space for plasma and other blood } \\
\text { product infusions and nutrition }\end{array}$ \\
$\begin{array}{l}\text { Urea cycle defects, and organic acidurias resulting in } \\
\text { hyperammonaemia, methymalonic acidaemia }\end{array}$ & $\begin{array}{c}\text { Severe poisoning or drug overdose } \\
\text { Severe hypothermia or hyperthermia }\end{array}$
\end{tabular}


initiation of CRRT in post cardiac surgery patients with a urine output of $<100 \mathrm{~mL} / 8 \mathrm{hr}[10,11]$. A recent observational study from the US multi-centre PICARD group, reported that starting RRT at urea values $>27 \mathrm{mmol} / \mathrm{L}$ was associated with a two-fold increased risk of mortality [12]. However, a prospective randomised study of both dose and timing of initiation of CVVH did not show any survival advantage of early therapy [13]. An early start was defined as initiation within 12 hours of meeting the following criteria: a urine output $<30 \mathrm{ml} / \mathrm{hr}$ for $>6$ hours despite attempts at optimisation, and a measured urinary creatinine clearance $<20 \mathrm{ml} / \mathrm{min}$. Therapy was commenced in the late start group when a conventional indication was met (severe pulmonary oedema, urea $\left.>40 \mathrm{mmol} / \mathrm{l}, \mathrm{K}^{+}>6.5 \mathrm{mmol} / \mathrm{l}\right)$. The study was, however, underpowered.

A recent systematic review of the literature identified 23 studies including only 4 RCTs and 1 quasi-RCT [14]. Most of the other studies were comparative cohort studies and mainly retrospective. The primary meta-analysis of the RCTs, only, suggested a 36\% mortality risk reduction, although this was non-significant. Meta-analysis of cohort studies indicated a statistically significant mortality risk reduction. Both analyses were hampered by varying definitions of early and late starts and by the fact that studies encompassed at least 4 decades of experience and widely different populations. Further prospective observational studies, published subsequent to this meta-analysis have yielded conflicting results $[15,16]$.

Finally, the evidence base for discontinuation of renal support with recovering renal function is even less clear than that for its initiation. A post hoc analysis from an international, multi-centre study found that urine output at the time of first stopping CRRT was the most important predictor of sustained discontinuation, especially if not enhanced by diuretics. Those who returned to RRT within 7 days had a higher mortality than those who did not although this could have been due to an intercurrent deterioration in the patient's overall condition rather than early cessation of renal support [17].

Thus, the current consensus from retrospective and observational studies suggests that 'early' initiation of RRT in AKI is associated with improved patient survival, although this remains to be confirmed by adequately powered, prospective, randomised trials. In every day clinical practice, clinicians typically start RRT earlier in patients with multiple organ failure than in those with AKI alone. 


\section{References}

1 Conger JD. Does hemodialysis delay recovery from acute renal failure? Seminars in Dialysis 1990;3:146-148

-2 Teschan PE, Baxter CR, O’Brien TF, Freyhof JN, Hall WH. Prophylactic hemodialysis in the treatment of acute renal failure. Annals of internal medicine, 53:992-1016, 1960 [classical article]. J Am Soc Nephrol 1998;9:2384-2397

3 Easterling RE, Forland M. A five year experience with prophylactic dialysis for acute renal failure. Transactions - American Society for Artificial Internal Organs 1964;10:200-208

$\checkmark 4$ Fischer RP, Griffen WO, Jr., Reiser M, Clark DS. Early dialysis in the treatment of acute renal failure. Surgery, Gynecology \& Obstetrics 1966;123:1019-1023

5 Parsons FM, Hobson SM, Blagg CR, McCracken BH. Optimum time for dialysis in acute reversible renal failure. Description and value of an improved dialyser with large surface area. Lancet 1961;1:129-134

6 Kleinknecht D, Jungers P, Chanard J, Barbanel C, Ganeval D. Uremic and non-uremic complications in acute renal failure: Evaluation of early and frequent dialysis on prognosis. Kidney Int 1972;1:190-196

$\checkmark 7$ Conger JD. A controlled evaluation of prophylactic dialysis in posttraumatic acute renal failure. Journal of Trauma-Injury Infection \& Critical Care 1975;15:1056-1063

8 Gillum DM, Dixon BS, Yanover MJ, Kelleher SP, Shapiro MD, Benedetti RG, Dillingham MA, Paller MS, Goldberg JP, Tomford RC. The role of intensive dialysis in acute renal failure. Clin Nephrol 1986;25: 249-255

9 Gettings LG, Reynolds HN, Scalea T. Outcome in post-traumatic acute renal failure when continuous renal replacement therapy is applied early vs. Late. Intensive Care Medicine 1999;25:805-813

10 Demirkilic U, Kuralay E, Yenicesu M, Caglar K, Oz BS, Cingoz F, Gunay C, Yildirim V, Ceylan S, Arslan M, Vural A, Tatar H. Timing of replacement therapy for acute renal failure after cardiac surgery. J Card Surg 2004;19:17-20
11 Elahi MM, Lim MY, Joseph RN, Dhannapuneni RR, Spyt TJ. Early hemofiltration improves survival in post-cardiotomy patients with acute renal failure. Eur J Cardiothorac Surg 2004;26:1027-1031

12 Liu KD, Himmelfarb J, Paganini E, Ikizler TA, Soroko SH, Mehta RL, Chertow GM. Timing of initiation of dialysis in critically ill patients with acute kidney injury Clin J Am Soc Nephrol 2006;1:915-919

13 Bouman CS, Oudemans-Van Straaten HM, Tijssen JG, Zandstra DF, Kesecioglu J. Effects of early high-volume continuous venovenous hemofiltration on survival and recovery of renal function in intensive care patients with acute renal failure: A prospective, randomized trial. Crit Care Med 2002;30:2205-2211

- 14 Seabra VF, Balk EM, Liangos O, Sosa MA, Cendoroglo M, Jaber BL. Timing of renal replacement therapy initiation in acute renal failure: A meta-analysis. Am J Kidney Dis 2008;52:272-284

15 Bagshaw SM, Uchino S, Bellomo R, Morimatsu H, Morgera S, Schetz M, Tan I, Bouman C, Macedo E, Gibney N, Tolwani A, Oudemans-van Straaten HM, Ronco C, Kellum JA. Beginning and Ending Supportive Therapy for the Kidney I: Timing of renal replacement therapy and clinical outcomes in critically ill patients with severe acute kidney injury. Journal of Critical Care 2009;24:129-140

16 Shiao CC, Wu VC, Li WY, Lin YF, Hu FC, Young GH, Kuo CC, Kao TW, Huang DM, Chen YM, Tsai PR, Lin SL, Chou NK, Lin TH, Yeh YC, Wang CH, Chou A, Ko WJ, Wu KD, National Taiwan University Surgical Intensive Care Unit-Associated Renal Failure Study G. Late initiation of renal replacement therapy is associated with worse outcomes in acute kidney injury after major abdominal surgery. Critical Care (London, England) 2009;13:R171

17 Uchino S, Bellomo R, Morimatsu H, Morgera S, Schetz M, Tan I, Bouman C, Macedo E, Gibney N, Tolwani A, Straaten HO, Ronco C, Kellum JA. Discontinuation of continuous renal replacement therapy: A post hoc analysis of a prospective multicenter observational study. Crit Care Med 2009;37:2576-2582 


\section{Acute Kidney Injury (AKI) (Guideline AKI 12.1)}

\section{Guideline 12.1 - AKI: Education}

We recommend that undergraduate and postgraduate medical trainees should be taught the principles of prevention and treatment of AKI. (1C)

\section{Rationale}

Acute kidney injury may be encountered in all branches of medicine and the opportunity to teach trainees should be embraced by nephrologists. The NCEPOD adding insult to injury AKI study recommended that both undergraduate and postgraduate

\section{References}

1 National Confidential Enquiry into Patient Outcome and Death, Adding Insult to Injury 2009. www.ncepod.org

2 Ali M, Lewington AJP. Do medical trainees receive adequate training in

\section{Acknowledgements}

The authors wish to thank the following individuals for providing helpful feedback on this guideline:

Dr Mike Jones and Dr Sian Finlay on behalf of Society for Acute Medicine

Dr Tim Gould on behalf of the Intensive Care Society

Mr Nicholas Palmer on behalf of the National Kidney Federation medical training for all specialties should include the recognition of the acutely ill patients and the prevention, diagnosis and management of AKI [1]. There is other supportive evidence that currently medical trainees do not receive adequate training in the management of AKI [2].

The importance of the association between small rises in serum creatinine and adverse patient outcomes should be highlighted. Medical students and trainees should be taught the principles of volume assessment and fluid prescribing. There should be a consolidation of interspecialty training and an emphasis on the development of AKI in the acutely ill patient.

the management of acute kidney injury? Abstract. American Society of Nephrology 2010

This guideline on AKI has been endorsed by the Society of Acute Medicine and the Intensive Care Society.

\section{Declarations of interest}

The authors do not have any perceived conflicts of interest to declare. 